\title{
A comprehensive molecular phylogeny of Geometridae (Lepidoptera) with a focus on enigmatic small subfamilies
}

\author{
Leidys Murillo-Ramos ${ }^{\text {Corresp., 1, }}{ }^{2}$, Gunnar Brehm ${ }^{3}$, Pasi Sihvonen ${ }^{4}$, Axel Hausmann ${ }^{5}$, Sille Holm ${ }^{6}$, Hamid Reza \\ Ghanavi $^{2}$, Erki Õunap ${ }^{6,7}$, Andro Truuverk $^{8}$, Hermann Staude $^{9}$, Egbert Friedrich ${ }^{10}$, Toomas Tammaru ${ }^{6}$, Niklas $^{2}$ \\ Wahlberg ${ }^{\text {Corresp. } 2}$ \\ ${ }^{1}$ Grupo Biología Evolutiva, department of Biology, Universidad de Sucre, Sincelejo, Sucre, Colombia \\ 2 Systematic Biology group, Department of Biology, Lund University, Lund, Sweden \\ 3 Institut für Zoologie und Evolutionsbiologie, Phyletisches Museum, Jena, Germany \\ 4 Finnish Museum of Natural History, University of Helsinki, Helsinki, Finland \\ 5 Staatliche Naturwissenschaftliche Sammlungen Bayerns, München, Germany \\ 6 Department of Zoology, Institute of Ecology and Earth Sciences, University of Tartu, Tartu, Vanemuise, Estonia \\ 7 Estonian University of Life Sciences, Institute of Agricultural and Environmental Sciences, Tartu, Kreutzwaldi, Estonia \\ 8 Natural History Museum, University of Tartu, Tartu, Vanemuise, Estonia \\ 9 LepsocAfrica, Magaliesburg, South Africa \\ 10 Berghoffsweg 5, Jena, Germany \\ Corresponding Authors: Leidys Murillo-Ramos, Niklas Wahlberg \\ Email address: leidys.murillo@unisucre.edu.co, niklas.wahlberg@biol.lu.se
}

Our study aims to investigate the relationships of the major lineages within the moth family Geometridae, with a focus on the poorly studied Oenochrominae-Desmobathrinae complex, and to translate some of the results into a coherent subfamilial and tribal level classification for the family. We analyzed a molecular dataset of 1206 Geometridae terminal taxa from all biogeographical regions comprising up to 11 molecular markers that includes one mitochondrial (COI) and 10 protein-coding nuclear gene regions (wingless, ArgK, MDH, RpS5, GAPDH, IDH, Ca-ATPase, Nex9, EF-1alpha, CAD). The molecular data set was analyzed using maximum likelihood as implemented in IQ-TREE and RAXML. We found high support for the subfamilies Larentiinae, Geometrinae and Ennominae in their traditional scopes. Sterrhinae becomes monophyletic only if Ergavia Walker, Ametris Hübner and Macrotes Westwood, which are currently placed in Oenochrominae, are formally transferred to Sterrhinae. Desmobathrinae and Oenochrominae are found to be polyphyletic. The concepts of Oenochrominae and Desmobathrinae required major revision and, after appropriate rearrangements, these groups also form monophyletic subfamilylevel entities. Oenochrominae s. str. as originally conceived by Guenée is phylogenetically distant from Epidesmia. The latter is hereby described as the subfamily Epidesmiinae Murillo-Ramos, Sihvonen \& Brehm, subfam. nov. Epidesmiinae are a lineage of "slenderbodied Oenochrominae" that include the genera Ecphyas Turner, Systatica Turner, Adeixis 
Warren, Dichromodes Guenée, Phrixocomes Turner, Abraxaphantes Warren, Epidesmia Duncan [\& Westwood] and Phrataria Walker. Archiearinae are monophyletic when Dirce and Acalyphesare formally transferred to Ennominae. We also found that many tribes were para- or polyphyletic and therefore propose tens of taxonomic changes at the tribe and subfamily levels. Archaeobalbini stat. rev. Viidalepp (Geometrinae) is raised from synonymy with Pseudoterpnini Warren to tribal rank. Chlorodontoperini Murillo-Ramos, Sihvonen \& Brehm, trib. nov. and Drepanogynini Murillo-Ramos, Sihvonen \& Brehm, trib. nov. are described as new tribes in Geometrinae and Ennominae, respectively. 


\section{Manuscript Title}

2

3 A comprehensive molecular phylogeny of Geometridae (Lepidoptera) with a focus on enigmatic

4 small subfamilies

5

6 Leidys Murillo-Ramos ${ }^{1,2}$, Gunnar Brehm ${ }^{3}$, Pasi Sihvonen ${ }^{4}$, Axel Hausmann ${ }^{5}$, Sille Holm ${ }^{6}$,

7 Hamid Reza Ghanavi ${ }^{2}$, Erki Õunap ${ }^{6,7}$, Andro Truuverk ${ }^{6,8}$, Hermann Staude ${ }^{9}$, Egbert Friedrich ${ }^{10}$,

8 Toomas Tammaru ${ }^{6}$, Niklas Wahlberg ${ }^{2}$.

$10{ }^{1}$ Grupo Biología Evolutiva, Department of Biology, Universidad de Sucre, Sincelejo, Sucre, 11 Colombia.

12 2Systematic Biology group, Department of Biology, Lund University, Lund, Sweden.

13 Institut für Zoologie und Evolutionsbiologie, Phyletisches Museum, Jena, Germany.

$14{ }^{4}$ Finnish Museum of Natural History, University of Helsinki, Helsinki, Finland.

$15{ }^{5}$ Staatliche Naturwissenschaftliche Sammlungen Bayerns, München, Germany

$16{ }^{6}$ Department of Zoology, Institute of Ecology and Earth Sciences, University of Tartu,

17 Vanemuise 46, 51014 Tartu, Estonia.

$18{ }^{7}$ Institute of Agricultural and Environmental Sciences, Estonian University of Life Sciences,

19 Kreutzwaldi 5, 51014 Tartu, Estonia.

$20{ }^{8}$ Natural History Museum, University of Tartu, Vanemuise 46, 51014 Tartu, Estonia

$21{ }^{9}$ LepsocAfrica, Magaliesburg, South Africa

$22{ }^{10}$ Berghoffsweg 5, 07743 Jena, Germany.

23

24 Corresponding Authors:

$25{ }^{1}$ Leidys Murillo-Ramos

26 and ${ }^{2}$ Niklas Wahlberg

27 Email address: leidys.murillo@unisucre.edu.co, niklas.wahlberg@biol.lu.se 


\section{Abstract}

34 Our study aims to investigate the relationships of the major lineages within the moth family

35 Geometridae, with a focus on the poorly studied Oenochrominae-Desmobathrinae complex, and

36 to translate some of the results into a coherent subfamilial and tribal level classification for the

37 family. We analyzed a molecular dataset of 1206 Geometridae terminal taxa from all

38 biogeographical regions comprising up to 11 molecular markers that includes one mitochondrial

39 (COI) and 10 protein-coding nuclear gene regions (wingless, $\operatorname{Arg} K, \mathrm{MDH}, \mathrm{RpS5}, \mathrm{GAPDH}, \mathrm{IDH}$,

40 Ca-ATPase, Nex9, EF-1alpha, CAD). The molecular data set was analyzed using maximum

41 likelihood as implemented in IQ-TREE and RAxML. We found high support for the subfamilies

42 Larentiinae, Geometrinae and Ennominae in their traditional scopes. Sterrhinae becomes monophyletic only if Ergavia Walker, Ametris Hübner and Macrotes Westwood, which are currently placed in Oenochrominae, are formally transferred to Sterrhinae. Desmobathrinae and Oenochrominae are found to be polyphyletic. The concepts of Oenochrominae and Desmobathrinae required major revision and, after appropriate rearrangements, these groups also form monophyletic subfamily-level entities. Oenochrominae s.str. as originally conceived by Guenée is phylogenetically distant from Epidesmia. The latter is hereby described as the subfamily Epidesmiinae Murillo-Ramos, Sihvonen \& Brehm, subfam. nov. Epidesmiinae are a lineage of "slender-bodied Oenochrominae" that include the genera Ecphyas Turner, Systatica Turner, Adeixis Warren, Dichromodes Guenée, Phrixocomes Turner, Abraxaphantes Warren, Epidesmia Duncan [\& Westwood] and Phrataria Walker. Archiearinae are monophyletic when Dirce and Acalyphes are formally transferred to Ennominae. We also found that many tribes were para- or polyphyletic and therefore propose tens of taxonomic changes at the tribe and subfamily levels. Archaeobalbini stat. rev. Viidalepp (Geometrinae) is raised from synonymy with Pseudoterpnini Warren to tribal rank. Chlorodontoperini Murillo-Ramos, Sihvonen \& Brehm, trib. nov. and Drepanogynini Murillo-Ramos, Sihvonen \& Brehm, trib. nov. are described as new tribes in Geometrinae and Ennominae, respectively. 


\section{Introduction}

64 Geometridae are the second most species-rich family of Lepidoptera, with approximately 24,000 described species (number from Nieukerken et al., 2011 updated by the authors) found in all regions except Antarctica. The monophyly of Geometridae is well supported based on distinctive morphological characters (Cook \& Scoble, 1992; Scoble, 1992; Minet \& Scoble, 1999). In particular, adult members of the family possess paired tympanal organs at the base of the abdomen, while in larvae the prolegs are reduced to two pairs in almost all species, which causes the larvae to move in a looping manner (Minet \& Scoble, 1999).

The phylogenetic relationships of the major subdivisions of Geometridae have been studied based on molecular data, which have contributed to the understanding of the evolutionary relationships within the family (Abraham et al., 2001; Yamamoto \& Sota, 2007; Sihvonen et al., 2011). Eight subfamilies are recognized in Geometridae (Sihvonen et al., 2011). Several recent molecular and morphological studies have attempted to confirm the monophyly or clarify the taxonomy of most of these groups, for instance: Sterrhinae (Holloway, 1997; Hausmann, 2004; Sihvonen \& Kaila, 2004; Õunap et al., 2008), Larentiinae (Holloway, 1997; Mironov, 2003; Viidalepp, 2006, 2011; Hausmann \& Viidalepp, 2012; Õunap et al., 2016), Desmobathrinae (Holloway, 1996; Hausmann, 2001), Archiearinae (Hausmann, 2001; Young, 2006), Oenochrominae (Holloway, 1996; Scoble \& Edwards, 1990; Cook \& Scoble, 1992; Hausmann, 2001; Young, 2006), Geometrinae (Cook, 1993; Pitkin, 1996; Hausmann, 2001; Ban et al., 2018), Orthostixinae (Holloway, 1997) and Ennominae (Holloway, 1994; Pitkin, 2002; Beljaev, 2006; Young, 2006; Wahlberg et al., 2010; Õunap et al., 2011; Skou \& Sihvonen, 2015; Sihvonen et al., 2015), but questions remain. An important shortcoming is that our understanding of geometrid systematics is biased towards the long-studied European fauna, whereas the highest diversity of this family is in the tropics, which are still largely unexplored (Brehm et al., 2016). Many species remain undescribed and there are many uncertainties in the classification of tropical taxa.

One of the most comprehensive phylogenetic studies on Geometridae to date was published by Sihvonen et al. (2011). They analyzed a data set of 164 taxa and up to eight genetic markers, and the most species-rich subfamilies were confirmed as monophyletic. However, the systematic positions of Oenochrominae and Desmobathrinae remained uncertain due to low taxon sampling and genetic markers, and both subfamilies were suspected to be polyphyletic. 
94 Moreover, because of taxonomic uncertainty, many geometrid genera, especially among tropical 95 taxa, remained unassigned to any tribe.

96 This study is the first in a series of papers that investigate the phylogenetic relationships

97 of Geometridae on the basis of global sampling. Our dataset comprises 1192 terminal taxa of

98 Geometridae and 14 outgroup taxa, with samples from all major biomes, using up to 11

99 molecular markers. Our paper includes an overview of the relationships of the major lineages

100 within the family, with the particular aim of defining the limits and finding the phylogenetic

101 affinities of the subfamilies, with a focus on Oenochrominae and Desmobathrinae. Further

102 papers in the series will focus on particular subfamilies and regions, and will build upon the

103 taxonomic changes proposed in the present article: e.g., relationships in Sterrhinae (Sihvonen et

104 al., in prep), New World taxa (Brehm et al., submitted), Larentiinae (Õunap et al., in prep) and

105 the ennomine tribe Boarmiini (Murillo-Ramos et al., in prep).

106 Oenochrominae and Desmobathrinae are considered the most controversial subfamilies in

107 Geometridae. A close relationship of these subfamilies has been proposed both in morphological

108 (Meyrick, 1889; Cook \& Scoble, 1992; Holloway, 1996) and in molecular studies (Sihvonen et

109 al., 2011; Ban et al., 2018). In early classifications, species of Desmobathrinae and

110 Oenochrominae were included in the former family Monoctenidae (Meyrick, 1889). Meyrick

111 diagnosed them on the basis of the position of the R veins in the hindwing and $\mathrm{Sc}+\mathrm{R} 1$ in the

112 forewing (Scoble \& Edwards, 1990). However, the classification proposed by Meyrick was not

113 fully supported by subsequent taxonomic work (Scoble \& Edwards, 1990; Cook \& Scoble, 1992;

114 Holloway, 1996). Too often, Oenochrominae was used for geometrids that could not be placed in

115 other subfamilies, and at some point, even included Hedylidae, the moth-butterflies (Scoble,

116 1992). Unsurprisingly, many formerly classified in Oenochrominae have recently been shown to

117 be misplaced (Holloway, 1997; Staude, 2001; Sihvonen \& Staude, 2011; Staude \& Sihvonen,

118 2014). In Scoble \& Edwards (1990), the family concept of Oenochrominae was restricted to the

119 robust-bodied Australian genera, with one representative from the Oriental region. Scoble \&

120 Edwards (1990) were not able to find synapomorphies to define Monoctenidae sensu Meyrick,

121 and referred back to the original grouping proposed by Guenée (1858). They restricted

122 Oenochrominae to a core clade based on male genitalia: the diaphragm dorsal to the anellus is

123 fused with the transtilla to form a rigid plate. Additionally, Cook \& Scoble (1992) suggested that 
124 the circular form of the lacinia and its orientation parallel to the tympanum was apomorphic for 125 these robust-bodied Oenochrominae.

126 In an extensive morphological study, Holloway (1996) delimited the subfamily

127 Desmobathrinae to include species with appendages and slender bodies previously assigned to

128 Oenochrominae. According to Holloway (1996), Desmobathrinae comprises two tribes:

129 Eumeleini and Desmobathrini. However, no synapomorphies were found to link the two tribes.

130 Holloway (1996) noted that the modification of the tegumen of the male genitalia was variable in

131 both groups but that the reduction of cremastral spines in the pupa from eight to four in Ozola

132 Walker, 1861 and Eumelea Duncan [\& Westwood], 1841 provided evidence of a close

133 relationship between Eumeleini and Desmobathrini. Currently, 328 species ( 76 genera) are

134 included in Oenochrominae, and 248 species (19 genera) are assigned to Desmobathrinae

135 (Beccaloni et al., 2003; Sihvonen et al., 2011, 2015).

136 Most recent molecular phylogenies have shown Oenochrominae and Desmobathrinae to

137 be intermingled (Sihvonen et al., 2011; Ban et al., 2018), but previous taxon sampling was

138 limited to eight and four species, respectively. The poor taxon sampling and unresolved

139 relationships around the oenochromine and desmobathrine complex called for additional

140 phylogenetic studies to clarify the relationships of these poorly known taxa within Geometridae.

141 We hypothesize that both Oenochrominae and Desmobathrinae are para- or polyphyletic

142 assemblages, and we address this hypothesis with 29 terminal taxa of Oenochrominae and 11

143 representatives of Desmobathrinae, mostly from the Australian and Oriental Regions.

145 Material \& Methods

146 Material acquisition, taxon sampling and species identification

147 In addition to 461 terminal taxa with published sequences (see Supplemental data S1), we

148 included sequences from 745 terminal taxa in our study (Supplemental data S1). Representative

149 taxa of all subfamilies recognized in Geometridae were included, except for the small subfamily

150 Orthostixinae for which most molecular markers could not be amplified successfully. A total of

15193 tribes are represented in this study following recent phylogenetic hypotheses and

152 classifications (Sihvonen et al., 2011; Wahlberg et al., 2010; Sihvonen et al., 2015; Õunap et al.,

153 2016; Ban et al., 2018). In addition, 14 non-geometrid species belonging to other families of

154 Geometroidea were included as outgroups based on the hypothesis proposed by Regier et al. 
155 (2009; 2013). Where possible, two or more samples were included per tribe and genus,

156 especially for species-rich groups that are widely distributed and in cases where genera were

157 suspected to be poly- or paraphyletic. We emphasized type species or species similar to type

158 species, judged by morphological characters and/or genetic similarity of DNA barcodes in order

159 to better inform subsequent taxonomic work, to favor nomenclatorial stability and to establish

160 the phylogenetic positions of genera unassigned to tribes.

161 Sampled individuals were identified by the authors using appropriate literature, by

162 comparing them with type material from different collections, museums and DNA barcode

163 sequences. Moreover, we compiled an illustrated catalogue of all Archiearinae, Desmobathrinae

164 and Oenochrominae taxa included in this study, to demonstrate their morphological diversity and

165 to facilitate subsequent verification of our identifications. This catalogue contains images of all

166 analysed specimens of the above-mentioned taxa as well as photographs of the respective type

167 material (Supplemental data S2). Further taxa from other subfamilies will be illustrated in other

168 papers (Brehm et al. in prep., Sihvonen et al. in prep., Õunap et al. in prep.). Some of the studied

169 specimens could not yet be assigned to species, and their identifications are preliminary,

170 particularly for (potentially undescribed) tropical species. Taxonomic data, voucher IDs, number

171 of genes, current systematic placement, and references to relevant literature with regard to tribal

172 assignment, are shown in Supplemental data S1.

173

174 Molecular techniques

175

176 DNA was extracted from 1-3 legs of specimens either preserved in ethanol or dry. In a few

177 cases, other sources of tissue were used, such as parts of larvae. The remaining parts of

178 specimens were preserved as vouchers deposited in the collections of origin, both public and

179 private (eventually private material will be deposited in public museum collections). Genomic

180 DNA was extracted and purified using a NucleoSpin ${ }^{\circledR}$ Tissue Kit (MACHEREY-NAGEL),

181 following the manufacturer's protocol. DNA amplification and sequencing were carried out

182 following protocols proposed by Wahlberg \& Wheat (2008) and Wahlberg et al. (2016). PCR

183 products were visualized on agarose gels. PCR products were cleaned enzymatically with

184 Exonuclease I and FastAP Thermosensitive Alkaline Phosphatase (ThermoFisher Scientific) and

185 sent to Macrogen Europe (Amsterdam) for Sanger sequencing. One mitochondrial (cytochrome

Peer] reviewing PDF | (2019:01:34676:2:0:NEW 11 Jun 2019) 
186 oxidase subunit I, COI) and 10 protein-coding nuclear gene regions, carbamoylphosphate

187 synthetase (CAD), Ribosomal Protein S5 (RpS5), wingless (wgl), cytosolic malate

188 dehydrogenase (MDH), glyceraldehydes-3-phosphate dehydrogenase (GAPDH), Elongation

189 factor 1 alpha (EF-1alpha), Arginine Kinase (ArgK), Isocitrate dehydrogenase (IDH), sorting

190 nexin-9-like (Nex9), and sarco/endoplasmic reticulum calcium ATPase (Ca-ATPase), were

191 sequenced. To check for potential misidentifications, DNA barcode sequences were compared to

192 those in BOLD (Ratnasingham \& Hebert 2007) where references of more than 21,000 geometrid

193 species are available, some 10,000 of them being reliably identified to Linnean species names

194 (Ratnasingham \& Hebert, 2007). GenBank accession numbers for sequences used in this study

195 are provided in Supplemental data S1.

196

197

Alignment and cleaning sequences

198

199

Multiple sequence alignments were carried out in MAFFT as implemented in Geneious v.11.0.2

200 (Biomatters, http://www.geneious.com/) for each gene based on a reference sequence of

201 Geometridae downloaded from the database VoSeq (Peña \& Malm, 2012). The alignment of

202 each gene was carefully checked by eye relative to the reference sequence, taking into account

203 the respective genetic codes and reading frames. Heterozygous positions were coded with

204 IUPAC codes. Sequences with bad quality were removed from the alignments. Aligned

205 sequences were uploaded to VoSeq (Peña \& Malm, 2012) and then assembled into a dataset

206 comprising 1206 taxa. The final dataset had a concatenated length of 7665 bp including gaps. To

207 check for possible errors in alignments, potentially contaminated or identical sequences and

208 misidentifications, we constructed maximum likelihood trees for each gene. These preliminary

209 analyses were conducted using RAxML-HPC2 V.8.2.10 (Stamatakis, 2014) on the web-server

210 CIPRES Science Gateway (Miller et al., 2010). The final data set included at least three genes

211 per taxon except for Oenochroma vinaria (Guenée, 1858), Acalyphes philorites Turner, 1925,

212 Dirce lunaris (Meyrick, 1890), D. aesiodora Turner, 1922, Furcatrox australis (Rosenstock,

213 1885), Chlorodontopera mandarinata (Leech, 1889), Chlorozancla falcatus (Hampson, 1895),

214 Pamphlebia rubrolimbraria (Guenée, 1858) and Thetidia albocostaria (Bremer, 1864). For these

215 taxa, included in studies by Young (2006) and Ban et al. (2018), only two markers were

216 available. The final data matrix included $32 \%$ missing data.

Peer] reviewing PDF | (2019:01:34676:2:0:NEW 11 Jun 2019) 
218 Tree search strategies and model selection

219 We ran maximum likelihood analyses with a data set partitioned by gene and codon position

220 using IQ-TREE V1.6.10 (Nguyen et al., 2015) and data partitioned by codon in RAxML

221 (Stamatakis et al 2014). Best-fitting substitution models were selected by ModelFinder, which is

222 a model-selection method that incorporates a model of flexible rate heterogeneity across sites

223 (Kalyaanamoorthy et al., 2017). ModelFinder implements a greedy strategy as implemented in

224 PartitionFinder that starts with the full partitioned model and consequentially merges partitions

225 (MFP+MERGE option) until the model fit does not increase (Lanfear et al., 2012). After the best

226 model has been found, IQ-TREE starts the tree reconstruction under the best model scheme. The

227 phylogenetic analyses were carried out with the -spp option that allowed each partition to have

228 its own evolutionary rate. The RAxML-HPC2 V.8.2.10 analysis was carried out on CIPRES

229 using the GTR+CAT option.

230 Support for nodes was evaluated with 1000 ultrafast bootstrap (UFBoot2) approximations

231 (Hoang et al., 2017) in IQ-TREE, and SH-like approximate likelihood ratio test (Guindon et al.,

232 2010). Additionally, we implemented rapid bootstrap (RBS) in RAxML (Stamatakis, 2008). To

233 reduce the risk of overestimating branch supports in UFBoot2 test, we implemented -bnni option,

234 which optimizes each bootstrap tree using a hill-climbing nearest neighbor interchange (NNI)

235 search. Trees were visualized and edited in FigTree v1.4.3 software (Rambaut, 2012). The final

236 trees were rooted with species of the families Sematuridae, Epicopeiidae, Pseudobistonidae and

237 Uraniidae following previous hypotheses proposed in Regier et al. (2009; 2013), Rajaei et al.

238 (2015) and Heikkilä et al. (2015).

\section{Taxonomic decisions}

240 The electronic version of this article in Portable Document Format (PDF) will represent a

241 published work according to the International Commission on Zoological Nomenclature (ICZN),

242 and hence the new names contained in the electronic version are effectively published under that

243 Code from the electronic edition alone. This published work and the nomenclatural acts it

244 contains have been registered in ZooBank. The ZooBank LSIDs (Life Science Identifiers) can be

245 resolved and the associated information viewed through any standard web browser by appending 
246 the LSID to the prefix http://zoobank.org/. For this publication: LSIDurn:1

247 sid:zoobank.org:pub:662A9A18-B620-45AA-B4B1-326086853316. The online version of this

248 work is archived and available from the following digital repositories: PeerJ, PubMed Central

249 and CLOCKSS.

250

251 Results

252

253

Searching strategies and model selection

254

255

256

The ModelFinder analysis resulted in 26 partitions with associated best-fit models (Table 1). IQ-

257

TREE and RAxML analyses resulted in trees with nearly identical topology. Also, the different

methods of evaluating robustness tended to agree in supporting the same nodes. However, in

259

most of the cases UFBoot2 from IQ-TREE showed higher support values compared to RBS in

260

RAxML (RAxML tree with support values is shown in Supplemental data S3). SH-like and

261

UFBoot2 performed similarly, with UFBoot2 showing slightly higher values, and both tended to

261

show high support for the same nodes (Fig. 1). As noted by the authors of IQ-TREE, values of

262

$\mathrm{SH}>=80$ and UFBoot2 $>=95$ indicate well-supported clades (Trifinopoulos \& Minh, 2018).

263

264

General patterns in the phylogeny of Geometridae

265

266

Analyses of the dataset of 1206 terminal taxa, comprising up to 11 markers and an

267

alignment length of $7665 \mathrm{bp}$ recovered topologies with many well-supported clades. About 20

268

terminal taxa are recovered as very similar genetically and they are likely to represent closely

269

related species, subspecies or specimens of a single species. The examination of their taxonomic

270

status is not the focus of this study, so the number of unique species in the analysis is slightly

271 less than 1200. Our findings confirm the monophyly of Geometridae (values of SH-like,

272 UFBoot2=100) (Fig. 1). The general patterns in our phylogenetic hypotheses suggest that

273 Sterrhinae are the sister group to the rest of Geometridae. This subfamily is recovered as

274 monophyletic when three genera traditionally included in Oenochrominae are considered to

275 belong to Sterrhinae (see details below). Tribes in Sterrhinae, such as Timandriini,

276 Rhodometrini, Lythriini, Rhodostrophiini and Cyllopodini, are not recovered as monophyletic 
277 (Fig. 2). A detailed analysis, including formal changes to the classification of Sterrhinae, will be 278 provided by Sihvonen et al. (in prep).

279 The monophyly of Larentiinae is established in previous studies (Sihvonen et al., 2011;

280 Õunap et al., 2016) and our results are largely in agreement with their hypotheses. However, our 281 results do not support the sister relationship between Sterrhinae and Larentiinae found in 282 previous studies. Rather, we find that Sterrhinae are the sister to the rest of Geometridae. Within 283 Larentiinae, in concordance with recent findings (Sihvonen et al., 2011; Õunap et al. 2016; 284 Strutzenberger et al., 2017), we find Dyspteridini as the sister group to the remaining Larentiinae 285 (Fig. 3). Phylogenetic relationships within Larentiinae were treated in detail by Õunap et al. 286 (2016). Further details of the analyses and changes to the classification of Larentiinae will be 287 discussed by Brehm et al. (submitted) and Õunap et al. (in prep).

288 Archiearinae are represented by more taxa than in a previous study (Sihvonen et al., 289 2011). Archiearinae grouped as sister to Oenochrominae + Desmobathrinae complex + Eumelea 290 + Geometrinae and Ennominae (Fig. 4). The monophyly of this subfamily is well supported 291 (values of SH-like, UFBoot2 = 100). However, as in the previous study (Sihvonen et al. 2011), 292 the Australian genera Dirce Prout, 1910 and Acalyphes Turner, 1926 are not part of Archiearinae 293 but can clearly be assigned to Ennominae. Unlike previously assumed (e.g., McQuillan \& 294 Edwards 1994), the subfamily Archiearinae probably does not occur in Australia, despite 295 superficial similarities of Dirce, Acalyphes and Archiearinae.

296 Desmobathrinae were shown to be paraphyletic by Sihvonen et al. (2011). In our 297 analysis, the monophyly of this subfamily is not recovered either, as we find two genera 298 traditionally placed in Oenochrominae (i.e. Zanclopteryx Herrich-Schäffer, [1855] and Racasta 299 Walker, 1861) nested within Desmobathrinae (Fig. 4). We formally transfer these genera to 300 Desmobathrinae. In the revised sense, Desmobathrinae form a well-supported group with two 301 main lineages. One of them comprises Ozola Walker, 1861, Derambila Walker, [1863] and 302 Zanclopteryx. This lineage is sister to a well-supported clade comprising Conolophia Warren, 303 1894, Noreia Walker, 1861, Leptoctenopsis Warren, 1897, Racasta, Ophiogramma Hübner, 304 [1831], Pycnoneura Warren, 1894 and Dolichoneura Warren, 1894.

305 Oenochrominae in the broad sense are not a monophyletic group. However, 306 Oenochrominae sensu stricto (Scoble \& Edwards, 1990) form a well-supported lineage 307 comprising two clades. One of them contains a polyphyletic Oenochroma with $O$. infantilis 
308 Prout, 1910 being sister to Dinophalus Prout, 1910, Hypographa Guenée, [1858], Lissomma

309 Warren, 1905, Sarcinodes Guenée, [1858] and two further species of Oenochroma, including the

310 type species O. vinaria Guenée, [1858]. The other clade comprises Monoctenia Guenée, [1858],

311 Onycodes Guenée, [1858], Parepisparis Bethune-Baker, 1906, Antictenia Prout, 1910, Arthodia

312 Guenée, [1858], Gastrophora Guenée, [1858] and Homospora Turner, 1904 (Fig. 4). Most of the

313 remaining genera traditionally placed in Oenochrominae, including e.g. Epidesmia Duncan [\&

314 Westwood], 1841, form a well-supported monophyletic clade that is sister to Oenochrominae $s$.

315 str. + Eumelea ludovicata + Geometrinae + Ennominae assemblage.

316 The genus Eumelea Duncan [\& Westwood], 1841 has an unclear phylogenetic position in our

317 analyses. The IQ-TREE result suggests Eumelea to be sister to the subfamily Geometrinae (SH-

318 like $=93.6$, UFBoot2 $=71$, whereas RAxML recovered Eumelea in Ennominae as sister of

319 Plutodes Guenée, [1858] (RBS = 60).

320 The monophyly of Geometrinae is well supported (Fig. 5) and in IQ-TREE results

321 Geometrinae are recovered as the sister-taxon of Eumelea. The Eumelea + Geometrinae clade is

322 sister to Oenochrominae s. str. Although a recent phylogenetic study proposed several taxonomic

323 changes (Ban et al., 2018), the tribal composition in Geometrinae is still problematic. Many

324 tribes are recovered as paraphyletic. Our results suggest that Ornithospila Warren, 1894 and

325 Agathia Guenée, [1858] are the sister lineage to the rest of Geometrinae. Chlorodontopera is

326 placed as an isolated lineage sister to Aracimini, Neohipparchini, Timandromorphini, Geometrini

327 and Comibaenini which are recovered as monophyletic groups, respectively. Synchlorini are

328 nested within Nemoriini in a well-supported clade (support branch SH-like $=98.3$, UFBoot2=

329 91, RBS = 93). The monophyly of Pseudoterpnini could not be recovered, instead this tribe splits

330 up into three well-defined groups. Several genera currently placed in Pseudoterpnini s.l. are

331 recovered as an independent lineage clearly separate from Pseudoterpnini s.str. (SH-like,

332 UFBoot2 =100). Xenozancla Warren, 1893 is sister to a clade comprising Dysphaniini and

333 Pseudoterpnini s.str. Hemitheini sensu Ban et al. (2018) are recovered as a well-supported clade.

334 The African Lophostola Prout, 1912 and Crypsiphona ocultaria Meyrick, 1888 were resolved as

335 a single lineage, close to Hemitheini.

336 Ennominae are strongly supported as monophyletic in IQ-TREE analyses (SH-like = 100,

337 UFBoot2=99) whereas in RAxML the monophyly is weakly supported (RBS = 63). Detailed

338 results concerning the classification, especially for the Neotropical taxa, will be presented by 
339 Brehm et al. (submitted), but the main results are summarized here (Fig. 6). Very few tribes are

340 monophyletic according to the results of the present study. One group of Neotropical taxa

341 currently assigned to Gonodontini (unnamed E1), Idialcis Warren 1906 (unnamed clade E2),

342 Gonodontini s.str., Gnophini, Odontoperini, unnamed clade E3, Nacophorini, and Ennomini

343 (sensu Beljaev, 2008) group together $(\mathrm{SH}-1 \mathrm{k} e=90.3$, UFBoot2 = 87). Ennomini were sister to

344 this entire group. Campaeini is recovered as sister of Alsophilini + Wilemaniini and Colotoini. In

345 turn they are sister to a clade comprising a number of taxa. These include the New Zealand genus

346 Declana Walker, 1858 (unnamed E4) which appear as sister to a large complex including

347 Acalyphes Turner, 1926 + Dirce Prout, 1910, Lithinini, intermixed with some genera currently

348 placed in Nacophorini and Diptychini.

349 Neobapta Warren, 1904 and Oenoptila Warren, 1895 form an independent lineage

350 (unnamed E5) sister to Theriini, which in turn form a supported clade with Lomographa

351 (Baptini) (SH-like, UFBoot2 = 100). Likewise, we recovered Erastria Hübner, [1813]+

352 Metarranthis Warren, 1894 (unnamed E6) and Plutodes Guenée, [1858] + Palyadini. The IQ-

353 TREE analyses show Palyadini as a well-defined lineage, sister to Plutodes. However, in

354 RAxML analyses, Eumelea and Plutodes group together and Palyadini cluster with a group of

355 Caberini species. Apeirini formed a lineage with Hypochrosini, Epionini, Sericosema Warren,

3561895 and Ithysia Hübner, [1825]. This lineage is in turn sister of African Drepanogynis Guenée,

357 [1858] which groups together with Sphingomima Warren, 1899, Thenopa Walker, 1855 and

358 Hebdomophruda Warren, 1897. Caberini are sister to an unnamed clade composed of Trotogonia

359 Warren, 1905, Acrotomodes Warren, 1895, Acrotomia Herrich-Schäffer, [1855] and Pyrinia

360 Hübner, 1818. Finally, our analyses recover a very large, well-supported clade comprising the

361 tribes Macariini, Cassymini, Abraxini, Eutoeini and Boarmiini (SH-like = 100, UFBoot2 = 99).

362 This large clade has previously been referred to informally as the "boarmiines" by Forbes (1948)

363 and Wahlberg et al. (2010). The tribe Cassymini is clearly paraphyletic: genera such as

364 Cirrhosoma Warren, 1905, Berberodes Guenée, 1858, Hemiphricta Warren, 1906 and

365 Ballantiophora Butler, 1881 currently included in Cassymini, cluster in their own clade together

366 with Dorsifulcrum Herbulot, 1979 and Odontognophos Wehrli, 1951. We were unable to include

367 Orthostixinae in the analyses, so we could not clarify the taxonomic position of this subfamily

368 with regard to its possible synonymy with Ennominae (Sihvonen et al., 2011). 


\section{Discussion}

371

372

Optimal partitioning scheme and support values

373 The greedy algorithm implemented in ModelFinder to select the best-fitting partitioning scheme

374 combined the codon partitions into 26 subsets (Table 2). These results are not different from

375 previous studies that tested the performance of different data partitioning schemes and found that

376 in some cases partitioning by gene can result in suboptimal partitioning schemes and may limit

377 the accuracy of phylogenetic analyses (Rota, 2011; Lanfear et al., 2012). However, we note that

378 although the AIC and BIC values were lower when the data were partitioned by gene, the tree

379 topology recovered was nevertheless almost the same as when data were partitioned by codon

380 position, suggesting that much of the phylogenetic signal in the data is robust to partitioning

381 schemes. As would be expected, the analyses resulted in some disagreements between the

382 different measures of node support. Ultrafast bootstrap gave the highest support values, followed

383 by SH-like and finally standard bootstrap as implemented in RAxML gave the lowest. Although

384 support indices obtained by these methods are not directly comparable, differences in node

385 support of some clades can be attributed to the small number of markers, insufficient

386 phylogenetic signal or saturated divergence levels (Guindon et al., 2010).

387

388 Current understanding of Geometridae phylogeny and taxonomic implications

389

390 Geometridae Leach, 1815

391 The phylogenetic hypothesis presented in this study is by far the most comprehensive to date in

392 terms of the number of markers, sampled taxa, and geographical coverage. In total, our sample

393 includes 814 genera, thus representing $41 \%$ of the currently recognised Geometridae genera

394 (Scoble \& Hausmann, 2007). Previous phylogenetic hypotheses were based mainly on the

395 European fauna and many clades were ambiguously supported due to low taxon sampling. The

396 general patterns of the phylogenetic relationships among the subfamilies recovered in our study

397 largely agrees with previous hypotheses based on morphological characters and different sets of

398 molecular markers (Holloway, 1997; Abraham, 2001; Yamamoto \& Sota, 2007; Sihvonen et al.,

399 2011). However, the results of our larger dataset differ in many details and shed light on the

400 phylogenetic relationships of several, poorly resolved, small subfamilies. 
Sterrhinae are recovered as the sister subfamily to the remaining Geometridae. This result

402 is not in concordance with Sihvonen et al. (2011), Yamamoto \& Sota (2007) and Regier et al.

403 (2009), who found a sister group relationship between Sterrhinae and Larentiinae which in turn

404 were sister to the rest of Geometridae. Sihvonen et al. (2011) showed the Sterrhinae +

405 Larentiinae sister relationship with low support, while Yamamoto \& Sota (2007) and Regier et

406 al. (2009) included only a few samples in their analyses. Our analyses include representatives

407 from almost all known tribes currently included in Sterrhinae and Larentiinae. The higher

408 number of markers, improved methods of analysis, the broader taxon sampling as well as the

409 stability of our results suggests that Sterrhinae are indeed the sister group to the remaining

410 Geometridae. Sterrhinae (after transfer of Ergavia, Ametris and Macrotes, see details below),

411 Larentiinae, Archiearinae, Geometrinae and Ennominae were highly supported as monophyletic.

412 Oenochrominae and Desmobathrinae formed polyphyletic and paraphyletic assemblages,

413 respectively. The monophylies of Oenochrominae and Desmobathrinae have long been

414 questioned. Morphological studies addressing Oenochrominae or Desmobathrinae have been

415 limited and the majority of genera have never been examined in depth. In addition, it has been

416 very difficult to establish the boundaries of these subfamilies on the basis of morphological

417 structures (Scoble \& Edwards, 1990). Sihvonen et al. (2011) showed that neither Oenochrominae

418 nor Desmobathrinae were monophyletic, but these results were considered preliminary due to the

419 limited number of sampled taxa, and as a consequence no formal transfers were proposed.

420 The systematic status of Orthostixinae remains uncertain because it was not included in

421 our study. Sihvonen et al. (2011) included the genus Naxa Walker, 1856, formally placed in

422 Orthostixinae, and found it to be nested within Ennominae. However, only three genes were

423 successfully sequenced from this taxon, and its position in the phylogenetic tree turned out to be

424 highly unstable in our analyses. It was thus excluded from our dataset. Orthostixis

425 Hübner, [1823], the type genus of the subfamily, needs to be included in future analyses.

426

427 Sterrhinae Meyrick, 1892

428 We included 74 Sterrhinae taxa in our analyses, with all tribes recognized in Forum Herbulot

429 (2007) being represented. The recovered patterns generally agree with previous phylogenetic

430 hypotheses of the subfamily (Sihvonen, 2004, Sihvonen et al., 2011). The genera Ergavia

431 Walker, 1866, Ametris Guenée, [1858] and Macrotes Westwood, 1841, which currently are

Peer] reviewing PDF | (2019:01:34676:2:0:NEW 11 Jun 2019) 
432 placed in Oenochrominae were found to form a well-defined lineage within Sterrhinae with 433 strong support (SH-Like $=99$ UFBoot2 $=100$ ). These genera are distributed in the New World, 434 whereas the range of true Oenochrominae is restricted to the Australian and Oriental Regions. 435 Sihvonen et al. (2011) already found that Ergavia and Afrophyla Warren, 1895 belong to 436 Sterrhinae and suggested more extensive analyses to clarify the position of these genera, which 437 we did. Afrophyla was transferred to Sterrhinae by Sihvonen \& Staude (2011) and Ergavia, 438 Ametris and Macrotes (plus Almodes Guenée, [1858]) will be transferred by Sihvonen et al. (in 439 prep.).

440 Cosymbiini, Timandrini, Rhodometrini and Lythriini are closely related as shown 441 previously (Sihvonen \& Kaila, 2004; Õunap et al., 2008; Sihvonen et al., 2011). Cosymbiini 442 appear as sister to the Timandrini + Traminda Saalmüller, 1891 + Pseudosterrha Warren, 1888 443 and Rhodometrini + Lythriini clade. Lythriini are closely related to Rhodometrini as shown by 444 Õunap et al. (2008) with both molecular and morphological data. Traminda (Timandrini) and 445 Pseudosterrha (Cosymbiini) grouped together forming a lineage that is sister to the Rhodometrini + Lythriini clade (Fig. 2).

447 Rhodostrophiini and Cyllopodini were recovered as polyphyletic with species of 448 Cyllopodini clustering within Rhodostrophiini. Similar results were recovered previously 449 (Sihvonen \& Kaila, 2004; Sihvonen et al., 2011), suggesting that additional work is needed to be 450 done to clarify the status and systematic positions of these tribes. Sterrhini and Scopulini were 451 recovered as sister taxa as proposed by Sihvonen \& Kaila (2004), Hausmann (2004), Õunap et al. 452 (2008) and Sihvonen et al. (2011). Our new phylogenetic hypothesis constitutes a large step 453 towards understanding the evolutionary relationships of the major lineages of Sterrhinae. Further 454 taxonomic changes and more detailed interpretation of the clades will be dealt with by Sihvonen 455 et al. (in prep.).

\section{Larentiinae Duponchel, 1845}

458 Larentiinae are a monophyletic entity (Fig. 3). In concordance with the results of Sihvonen et al. 459 (2011), Viidalepp (2011), Õunap et al. (2016) and Strutzenberger et al. (2017), Dyspteridini are 460 supported as sister to all other larentiines. Remarkably, Brabirodes Warren, 1904 forms an 461 independent lineage. Chesiadini are monophyletic and sister to all larentiines except 
462 Dyspteridini, Brabirodes and Trichopterygini. These results do not support the suggestion by 463 Viidalepp (2006) and Sihvonen et al. (2011) that Chesiadini are sister to Trichopterygini.

464 In our phylogenetic hypothesis, Asthenini are sister to the Perizomini + Melanthiini +

465 Eupitheciini clade. These results do not fully agree with Õunap et al. (2016) who found

466 Asthenini to be sister to all Larentiinae except Dyspteridini, Chesiadini, Trichopterygini and

467 Eudulini. However, our results do support the Melanthiini + Eupitheciini complex as a sister

468 lineage to Perizomini. Sihvonen et al. (2011) recovered Phileremini and Rheumapterini as well-

469 supported sister taxa. Our results suggest Triphosa dubitata Linnaeus 1758 (Triphosini) is sister

470 to Phileremini, with Rheumapterini sister to this clade. Cidariini were recovered as paraphyletic,

471 as the genera Coenotephria Prout, 1914 and Lampropteryx Stephens, 1831 cluster in a different

472 clade (unnamed clade L7) apart from the lineage comprising the type genus of the tribe, Cidaria

473 Treitschke, 1825. Ceratodalia Packard, 1876, currently placed in Hydriomenini and Trichodezia

474 Warren, 1895 nested within Cidariini. This result is not in concordance with Õunap et al. (2016),

475 who regarded this tribe to be monophyletic. Scotopterygini are sister to a lineage comprising

476 Ptychorrhoe blosyrata Guenée [1858], Disclisioprocta natalata (Walker, 1862) (placed in the

477 unnamed clade L8), Euphyiini, an unnamed clade L9 comprising the genera Pterocypha,

478 Archirhoe and Obila, Xanthorhoini and Cataclysmini. Euphyiini are monophyletic, but

479 Xanthorhoini are recovered as mixed with Cataclysmini. The same findings were shown by

480 Õunap et al. (2016), but no taxonomic rearrangements were proposed. Larentiini are

481 monophyletic and sister of Hydriomenini, Heterusiini, Erateinini, Stamnodini and some unnamed

482 clades (L11-14). Although with some differences, our results support the major phylogenetic

483 patterns of Õunap et al. (2016).

484 Despite substantial progress, the tribal classification and phylogenetic relationships of

485 Larentiinae are far from being resolved (Õunap et al. 2016). Forbes (1948) proposed eight tribes

486 based on morphological information, Viidalepp (2011) raised the number to 23 and Õunap et al.

487 (2016) recovered 25 tribes studying 58 genera. Our study includes 23 of the currently recognized

488 tribes and 125 genera (with an emphasis on Neotropical taxa). However, the phylogenetic

489 position of many taxa remains unclear, and some tropical genera have not yet been formally

490 assigned to any tribe. Formal descriptions of these groups will be treated in detail by Brehm et al.

491 (submitted) and Õunap et al. (in prep). 


\section{Archiearinae Fletcher, 1953}

494 The hypothesis presented in this study recovered Archiearinae as a monophyletic entity after 495 some taxonomic rearrangements are performed. This subfamily was previously considered as 496 sister to Geometrinae + Ennominae (Abraham et al., 2001), whereas Yamamoto \& Sota (2007)

497 proposed them to be the sister-taxon to Orthostixinae + Desmobathrinae. Our findings agree with 498 Sihvonen et al. (2011) who recovered Archiearinae as the sister-taxon to the rest of Geometridae 499 excluding Sterrhinae and Larentiinae, although only one species was included in their study.

500 Archiearis Hübner, [1823] is sister to Boudinotiana Esper, 1787 and these taxa in turn are sister 501 to Leucobrephos Grote, 1874 (Fig. 4). The southern hemisphere Archiearinae require more 502 attention. Young (2006) suggested that two Australian Archiearinae genera, Dirce and

503 Acalyphes, actually belong to Ennominae. Our analyses clearly support this view and we 504 therefore propose to formally transfer Dirce and Acalyphes to Ennominae (all formal taxonomic 505 changes are provided in Table 2). Unfortunately, the South American Archiearinae genera 506 Archiearides Fletcher, 1953 and Lachnocephala Fletcher, 1953, and Mexican Caenosynteles 507 Dyar, 1912 (Pitkin \& Jenkins 2004), could not be included in our analyses. These presumably 508 diurnal taxa may only be superficially similar to northern hemisphere Archiearinae as was the 509 case with Australian Dirce and Acalyphes.

510

\section{Desmobathrinae Meyrick, 1886}

512 Taxa placed in Desmobathrinae were formerly recognized as Oenochrominae genera with

513 slender appendages. Holloway (1996) revived Desmobathrinae from synonymy with

514 Oenochrominae and divided it into the tribes Eumeleini and Desmobathrini. Desmobathrinae

515 species have a pantropical distribution and they apparently (still) lack recognized morphological

516 apomorphies (Holloway, 1996). Our phylogenetic analysis has questioned the monophyly of

517 Desmobathrinae sensu Holloway because some species currently placed in Oenochrominae were

518 embedded within the group (see also Sihvonen et al., 2011), and also the phylogenetic position of

519 the tribe Eumeleini is unstable (see below). Desmobathrinae can be regarded as a monophyletic

520 group after the transfer of Zanclopteryx, Nearcha and Racasta from Oenochrominae to

521 Desmobathrinae, and the removal of Eumeleini (Table 2). Desmobathrinae as circumscribed here

522 are an independent lineage that is sister to all Geometridae except Sterrhinae, Larentiinae and 523 Archiearinae. 
524 The monobasic Eumeleini has had a dynamic taxonomic history: Eumelea was

525 transferred from Oenochrominae s.l. to Desmobathrinae based on the pupal cremaster

526 (Holloway, 1996), whereas Beljaev (2008) pointed out that Eumelea could be a member of

527 Geometrinae based on the skeleto-muscular structure of the male genitalia. Molecular studies

528 (Sihvonen et al., 2011, Ban et al., 2018) suggested that Eumelea was part of Oenochrominae

529 s.str., but these findings were not well-supported and no formal taxonomic changes were

530 proposed. Our analyses with IQTREE and RAxML recovered Eumeleini in two very different

531 positions, either as sister to Geometrinae ( $\mathrm{SH}-$ like $=93.6$, UFBoot2 $=71)($ figs 4,5$)$, or as sister

532 of Plutodes in Ennominae (RBS = 60) (Supplemental data S3). The examination of

533 morphological details suggests that the position as sister to Geometrinae is more plausible:

534 hindwing vein M2 is present and tubular; anal margin of the hindwing is elongated; and large

535 coremata originate from the saccus (Holloway 1994, our observations). The morphology of

536 Eumelea is partly unusual, and for that reason we illustrate selected structures (Supplemental

537 data S4), which include for instance the following: antennae and legs of both sexes are very long;

538 forewing vein Sc (homology unclear) reaches wing margin; in male genitalia coremata are

539 extremely large and branched; uncus is cross-shaped (cruciform); tegumen is narrow and it

540 extends ventrally beyond the point of articulation with vinculum; saccus arms are extremely

541 long, looped; and vesica is with lateral rows of cornuti. However, the green geoverdin pigment

542 concentration of Eumelea is low in comparison to Geometrinae (Cook et al., 1994). We

543 tentatively conclude that Eumelea is probably indeed associated with Geometrinae. However,

544 since eleven genetic markers were not sufficient to clarify the phylogenetic affinities of Eumelea,

545 we provisionally place the genus as incertae sedis (Table 2).

546

547 Oenochrominae Guenée, [1858]

548 Oenochrominae has obviously been the group comprising taxa that could not easily be assigned

549 to other subfamilies. Out of the 76 genera currently assigned to Oenochrominae, our study

550 includes 25 genera ( 28 species). Three of these genera will be formally transferred to Sterrhinae

551 (Sihvonen et al. in prep.), three are here transferred to Desmobathrinae (see above, Table 2), and

552 eight are transferred to Epidesmiinae (see below). In agreement with Sihvonen et al. (2011),

553 Oenochrominae s. str. grouped together in a well-supported lineage. Genera of this clade can be

554 characterized as having robust bodies, and their male genitalia have a well-developed uncus and 
555 gnathos, broad valvae and a well-developed anellus (Scoble \& Edwards, 1990). Common host 556 plants are members of Proteaceae and Myrtaceae (Holloway, 1996). Our results strongly suggest

557 that the genus Oenochroma is polyphyletic: $O$. infantilis is sister to a clade including

558 Dinophalus, Hypographa, Lissomma, Sarcinodes and (at least) two species of Oenochroma. To

559 date, 20 species have been assigned to Oenochroma by Scoble (1999), and one additional species

560 was described by Hausmann et al. (2009), who suggested that $O$. vinaria is a species complex.

561 We agree with Hausmann et al. (2009), who pointed out the need for a major revision of

562 Oenochroma.

563

564

565

566

567

568

569

570

571

572

573

574

575

576

577

578

579

580

581

582

583

584

In our phylogenetic hypothesis, Sarcinodes is sister to O. orthodesma and O. vinaria, the type species of Oenochroma. Although Sarcinodes and Oenochroma resemble each other in external morphology, a sister-group relationship between these genera has not been hypothesized before. The inclusion of Sarcinodes in Oenochrominae is mainly based on shared tympanal characters (Scoble \& Edwards, 1990). However, the circular form of the lacinia, which is an apomorphy of Oenochrominae s.str. is missing or not apparent in Sarcinodes (Holloway, 1996). In addition, Sarcinodes is found in the Oriental rather than in the Australian region, where all Oenochroma species are distributed. A second clade of Oenochrominae s.str. comprises the genera Monoctenia, Onycodes, Parepisparis, Antictenia, Arhodia, Gastrophora and Homospora, which clustered together as the sister of Oenochroma and its relatives. These genera are widely recognized in sharing similar structure of the male genitalia (Scoble \& Edwards, 1990), yet their phylogenetic relationships have never been tested. Young (2006) suggested the monophyly of Oenochrominae s.str., however, with a poorly resolved topology and low branch support. In her study, Parepisparis, Phallaria and Monoctenia shared a bifid head, while in Parepisparis and Onychodes, the aedeagus was lacking caecum and cornuti. Our analysis supports these morphological similarities. Monoctenia, Onycodes and Parepisparis clustered together. However, a close relationship of the genera Antictenia, Arhodia, Gastrophora and Homospora has not been suggested before. Our analysis thus strongly supports the earliest definition of Oenochrominae proposed by Guenée (1858), and reinforced by Cook \& Scoble (1992). Oenochrominae should be restricted to Oenochroma and related genera such as Dinophalus, Hypographa, Lissomma, Sarcinodes, Monoctenia, Onycodes, Parepisparis, Antictenia, Arhodia, Gastrophora, Homospora, Phallaria and Palaeodoxa. We consider that genera included in 
585 Oenochrominae by Scoble \& Edwards (1990), but recovered in a lineage separate from

586 Oenochroma and its close relatives in our study, belong to a hitherto unknown subfamily, which 587 is described below.

588

589 Epidesmiinae Murillo-Ramos, Brehm \& Sihvonen new subfamily

590 LSIDurn:1sid:zoobank.org:act:34D1E8F7-99F1-4914-8E12-0110459C2040

591 Type genus: Epidesmia Duncan [\&Westwood], 1841.

592 Material examined: Taxa included in the molecular phylogeny: Ecphyas holopsara Turner, 1929,

593 Systatica xanthastis Lower, 1894, Adeixis griseata Hudson 1903, Dichromodes indicataria

594 Walker 1866, Phrixocomes sp. Turner 1930, Abraxaphantes perampla Swinhoe 1890, Epidesmia

595 chilonaria Herrich-Schäffer [1855], Phrataria replicataria Walker 1866.

596 Most of the slender-bodied Oenochrominae, excluded from Oenochrominae s. str. by Holloway

597 (1996), were recovered as an independent lineage (Fig. 4) that consists of two clades: Ec.

598 holopsara + S. xanthastis and Ep. chilonaria + five other genera. Branch support values from

599 IQ-TREE strongly support the monophyly of this clade (SH-like and UFBoot2 = 100), while in

600 RAxML the clade is moderately supported $(\mathrm{RBS}=89)$. These genera have earlier been assigned

601 to Oenochrominae s.l. (Scoble \& Edwards, 1990). However, we recovered the group as a well-

602 supported lineage independent from Oenochrominae s. str. and transfer them to Epidesmiinae, 603 subfam. n. (Table 2).

604 Phylogenetic position: Epidesmiinae is sister to Oenochrominae s. str. + Eumelea + Geometrinae $605+$ Ennominae.

606 Short description of Epidesmiinae: Antennae in males unipectinate (exception: Adeixis), shorter

607 towards the apex. Pectination moderate or long. Thorax and abdomen slender (unlike in

608 Oenochrominae). Forewings with sinuous postmedial line and areole present. Forewings

609 planiform (with wings lying flat on the substrate) in resting position, held like a triangle, and

610 cover the hindwings.

611 Diagnosis of Epidesmiinae: The genera included in this subfamily form a strongly supported

612 clade with DNA sequence data from the following gene regions (exemplar Epidesmia chilonaria

613 Herrich-Schäffer, [1855]) ArgK (MK738299), Ca-ATPase (MK738690), CAD (MK738960),

614 COI (MK739187), EF1a (MK740168), GAPDH (MK740402), MDH (MK740974) and Nex9 
615 (MK741433). A thorough morphological investigation of the subfamily, including diagnostic 616 characters, is under preparation.

617 Distribution: Most genera are distributed in the Australian region, with some species ranging into 618 the Oriental region. Abraxaphantes occurs exclusively in the Oriental region.

619

\section{Geometrinae Stephens, 1829}

621 The monophyly of Geometrinae is strongly supported, but the number of tribes included 622 in this subfamily is still unclear. Sihvonen et al. (2011) analyzed 27 species assigned to 11 tribes, 623 followed by Ban et al. (2018) with 116 species in 12 tribes. Ban et al. (2018) synonymized nine 624 tribes, and validated the monophyly of 12 tribes, with two new tribes Ornithospilini and 625 Agathiini being the first two clades branching off the main lineage of Geometrinae. Our study 626 (168 species) validates the monophyly of 13 tribes, eleven of which were defined in previous 627 studies: Hemitheini, Dysphaniini, Pseudoterpnini s.str., Ornithospilini, Agathiini, Aracimini, 628 Neohipparchini, Timandromorphini, Geometrini, Comibaeini, Nemoriini. One synonymization is 629 proposed: Synchlorini Ferguson, 1969 syn. nov. is synonymized with Nemoriini Gumppenberg, 630 1887. One tribe is proposed as new: Chlorodontoperini trib. nov., and one tribe (Archaeobalbini 631 Viidalepp, 1981, stat. rev.) is raised from synonymy with Pseudoterpnini.

632 Ban et al. (2018) found that Ornithospila Warren, 1894 is sister to the rest of

633 Geometrinae, and Agathia Guenée, [1858] is sister to the rest of Geometrinae minus

634 Ornithospila. Although weakly supported, our results (with more species of Agathia sampled) 635 placed Ornisthospilini+Agathiini together and these tribes are the sister to the rest of

636 Geometrinae. Chlorodontopera is placed as an isolated lineage as shown by Ban et al. (2018).

637 Given that Chlorodontopera clearly forms an independent and well-supported lineage we 638 propose the description of a new tribe Chlorodontoperini.

639

640 Chlorodontoperini Murillo-Ramos, Sihvonen \& Brehm, new tribe

641 LSIDurn:1sid:zoobank.org:act:0833860E-A092-43D6-B2A1-FB57D9F7988D

642 Type genus: Chlorodontopera Warren, 1893

643 Material examined: Taxa in the molecular phylogeny: C. discospilata (Moore, 1867) and $C$. 644 mandarinata (Leech, 1889). 
645 Some studies (Inoue, 1961; Holloway, 1996) suggested the morphological similarities of 646 Chlorodontopera Warren, 1893 with members of Aracimini. Moreover, Holloway (1996) 647 considered this genus as part of Aracimini. Our results suggest a sister relationship of 648 Chlorodontopera with a large clade comprising Aracimini, Neohipparchini, Timandromorphini, 649 Geometrini, Nemoriini and Comibaenini. Considering that our analysis strongly supports 650 Chlorodontopera as an independent lineage (branch support SH-like $=99$ UFBoot2 $=100$, RBS 651 =99), we introduce the monobasic tribe Chlorodontoperini. This tribe can be diagnosed by the 652 combination of DNA data from six genetic markers (exemplar Chlorodontopera discospilata) 653 CAD (MG015448), COI (MG014735), EF1a (MG015329), GAPDH (MG014862), MDH 654 (MG014980) and RpS5 (MG015562). Ban et al. (2018) did not introduce a new tribe because the 655 relationship between Chlorodontopera and Euxena Warren, 1896 was not clear in their study. 656 This relationship was also been proposed by Holloway (1996) based on similar wing patterns. 657 Further analyses are needed to clarify the affinities between Chlorodontopera and Euxena. 658 The tribe Chlorodontoperini is diagnosed by distinct discal spots with pale margins on the 659 wings, which are larger on the hindwing; a dull reddish-brown patch is present between the 660 discal spot and the costa on the hindwing, and veins $\mathrm{M} 3$ and $\mathrm{CuA} 1$ are not stalked on the 661 hindwing (Ban et al., 2018). In the male genitalia, the socii are stout and setose and the lateral 662 arms of the gnathos are developed, not joined. Sternite 3 of the male has setal patches. Formal 663 taxonomic changes are listed in Table 2.

664 Aracimini, Neohipparchini, Timandromorphini, Geometrini and Comibaenini were recovered as 665 monophyletic groups. These results are in full agreement with Ban et al. (2018). However, the 666 phylogenetic position of Eucyclodes Warren, 1894 is uncertain (unnamed G2). The monophyly 667 of Nemoriini and Synchlorini is not supported. Instead, Synchlorini are nested within Nemoriini 668 (support branch SH-like $=98.3$, UFBoot $2=91$, RBS $=93$ ). Our findings are in concordance with 669 Sihvonen et al. (2011) and Ban et al. (2018), but our analyses included a larger number of 670 markers and a much higher number of taxa. Thus, we formally synonymize Synchlorini syn. 671 nov. with Nemoriini (Table 2).

672 The monophyly of Pseudoterpnini sensu Pitkin et al. (2007) could not be recovered.

673 Similar results were shown by Ban et al. (2018) who recovered Pseudoterpnini s.l. including all 674 the genera previously studied by Pitkin et al. (2007), forming a separate clade from 675 Pseudoterpna Hübner, [1823] + Pingasa Moore, 1887. Our results showed African Mictoschema 
676 Prout, 1922 falling within Pseudoterpnini s.str., and it is sister to Pseudoterpna and Pingasa. A 677 second group of Pseudoterpnini s.l. was recovered as an independent lineage clearly separate 678 from Pseudoterpnini s.str. (SH-like = 88.3, UFBoot2 =64). Ban et al. (2018) did not introduce a 679 new tribe due to the morphological similarities and difficulty in finding apomorphies of 680 Pseudoterpnini s.str. In addition, their results were weakly supported. Considering that two 681 independent studies have demonstrated the paraphyly of Pseudoterpnini sensu Pitkin et al (2007), 682 we see no reason for retaining the wide concept of this tribe. Instead, we propose the revival of 683 the tribe status of Archaeobalbini.

684

685 Archaeobalbini Viidalepp, 1981, status revised

686 (original spelling: Archeobalbini, justified emendation in Hausmann (1996))

687 Type genus: Archaeobalbis Prout, 1912 (synonymized with Herochroma Swinhoe, 1893 in 688 Holloway (1996))

689 Material examined: Herochroma curvata Han \& Xue, 2003, H. baba Swinhoe 1893, 690 Metallolophia inanularia Han \& Xue, 2004, M. cuneataria Han \& Xue, 2004, Actenochroma 691 muscicoloraria (Walker, 1862), Absala dorcada Swinhoe, 1893, Metaterpna batangensis Hang 692 \& Stüning, 2016, M. thyatiraria (Oberthür, 1913), Limbatochlamys rosthorni Rothschild, 1894, 693 Pachyodes pictaria Moore, 1888, Dindica para Swinhoe, 1893, Dindicodes crocina (Butler, 694 1880), Lophophelma erionoma (Swinhoe, 1893), L. varicoloraria (Moore, 1868), L. iterans 695 (Prout, 1926) and Pachyodes amplificata (Walker, 1862).

696

697 This lineage splits into four groups: Herochroma Swinhoe, $1893+$ Absala Swinhoe, $1893+$ 698 Actenochroma Warren, 1893 is the sister lineage of the rest of Archaeobalbini that were 699 recovered as three clades with unresolved relationships comprising the genera Limbatochlamys 700 Rothschild, 1894, Psilotagma Warren, 1894, Metallolophia Warren, 1895, Metaterpna Yazaki, 701 1992, Dindica Warren, 1893, Dindicodes Prout, 1912, Lophophelma Prout, 1912 and Pachyodes 702 Guenée, 1858. This tribe can be diagnosed by the combination of DNA data from six genetic 703 markers, see for instance Pachyodes amplificata CAD (MG015522), COI (MG014818), EF1a 704 (MG015409), GAPDH (MG014941), MDH (MG015057), and RpS5 (MG015638). Branch 705 support values in IQ-TREE confirm the monophyly of this clade $(\mathrm{SH}-$ like $=88.3$, UFBoot2 $=$ 
706 64). GenBank accession numbers are shown in supplementary material. A morphological

707 diagnosis requires further research.

708 Xenozancla Warren, 1893 (unnamed G3) is sister to the clade comprising Dysphaniini

709 and Pseudoterpnini s. str. Sihvonen et al. (2011) did not include Xenozancla in their analyses and

710 suggested a sister relationship of Dysphaniini and Pseudoterpnini, but with low support.

711 According to Ban et al. (2018), Xenozancla is more closely related to Pseudoterpnini s.str. than

712 to Dysphaniini. However, due to low support, Ban et al. (2018) did not propose a taxonomic

713 assignment for Xenozancla, which is currently not assigned to a tribe. Although our IQ-TREE

714 results show that Xenozancla is sister to a clade comprising Dysphaniini and Pseudoterpnini $s$.

715 str., the RAxML analysis did not recover the same phylogenetic relationships. Instead,

716 Dysphaniini + Pseudoterpnini s.str. are found to be sister taxa, but Xenozancla is placed close to

717 Rhomborista monosticta (Wehrli, 1924). As in Ban et al. (2018), our results do not allow us to

718 reach a conclusion about the phylogenetic affinities of these tribes, due to low support of nodes.

719 The Australian genus Crypsiphona Meyrick, 1888 (unnamed G4) was placed close to

720 Hemitheini. Crypsiphona has been assigned to Pseudoterpnini (e. g. Pitkin et al. 2007, Õunap \&

721 Viidalepp 2009), but is recovered as a separate lineage in our tree. Given the isolated position of

722 Crypsiphona, the designation of a new tribe could be considered, but due to low support of nodes

723 in our analyses, further information (including morphology) is needed to confirm the

724 phylogenetic position of this genus. In our phylogenetic hypothesis, a large clade including the

725 former tribes Lophochoristini, Heliotheini, Microloxiini, Thalerini, Rhomboristini, Hemistolini,

726 Comostolini, Jodini and Thalassodini is recovered as sister to the rest of Geometrinae. These

727 results are in full agreement with Ban et al. (2018), who synonymized all of these tribes with

728 Hemitheini. Although the monophyly of Hemitheini is strongly supported, our findings

729 recovered only a few monophyletic subtribes. For example, genera placed in Hemitheina were

730 intermixed with those belonging to Microloxiina, Thalassodina and Jodina. Moreover, many

731 genera which were unassigned to tribe, were recovered as belonging to Hemitheini. Our findings

732 recovered Lophostola Prout, 1912 as sister to all Hemitheini. These results are quite different

733 from those found by Ban et al. (2018) who suggested Rhomboristina as being sister to the rest of

734 Hemitheini. In contrast, our results recovered Rhomboristina mingled with Hemistolina. These

735 different results are probably influenced by the presence of African and Madagascan Lophostola 
736 in our analysis. We feel that the subtribe concept is not practical thus do not advocate its use in

737 geometrid classification.

738

739 Ennominae Duponchel, 1845

740 Ennominae are the most species-rich subfamily of geometrids. The loss of vein M2 on the

741 hindwing is probably the best apomorphy (Holloway, 1993), although this character does not

742 occur in a few ennomine taxa (Staude, 2001; Skou \& Sihvonen, 2015). Ennominae are a

743 morphologically highly diverse subfamily, and attempts to find further synapomorphies shared

744 by all major tribal groups have failed.

745 The number of tribes as well as phylogenetic relationships among tribes are still debated

746 (see Skou \& Sihvonen, 2015 for an overview). Moreover, the taxonomic knowledge of this

747 subfamily in tropical regions is still poor. Holloway (1993) recognized 21 tribes, Beljaev (2006)

74824 tribes, and Forum Herbulot (2007) 27 tribes. To date, four molecular studies have

749 corroborated the monophyly of Ennominae (Yamamoto \& Sota, 2007; Wahlberg et al., 2010;

750 Ounap et al., 2011, Sihvonen et al. 2011), with Young (2006) being the only exception who

751 found Ennominae paraphyletic. Moreover, three large-scale taxonomic revisions (without a

752 phylogenetic hypothesis) were published by Pitkin (2002) for the Neotropical region, Skou \&

753 Sihvonen (2015) for the Western Palaearctic region, and Holloway (1994) for Borneo. More

754 detailed descriptions of taxonomic changes in Ennominae will be given by Brehm et al.

755 (submitted) and Murillo-Ramos et al. (in prep.). We here discuss general patterns and give

756 details for taxonomic acts not covered in the other two papers.

757 Our findings recover Ennominae as a monophyletic entity, but results were not highly

758 supported in RAxML (RBS =67) results compared to IQ-TREE (SH-Like =100, UFBoot2=99).

759 The lineage comprising Geometrinae and Oenochrominae is recovered as the sister clade of

760 Ennominae. In previous studies, Wahlberg et al. (2010) sampled 49 species of Ennominae,

761 Õunap et al. (2011) sampled 33 species, and Sihvonen et al. (2011) 70 species including up to

762 eight markers per species. All these studies supported the division of Ennominae into

763 "boarmiine" and "ennomine" moths (Holloway, 1994). This grouping was proposed by Forbes

764 (1948) and Holloway (1994), who suggested close relationships between the tribes Boarmiini,

765 Macariini, Cassymini and Eutoeini based on the bifid pupal cremaster and the possession of a

766 fovea in the male forewing. The remaining tribes were defined as "ennomines" based on the loss 
767 of a setal comb on male sternum A3 and the presence of a strong furca in male genitalia. Both

768 Wahlberg et al. (2010) and Sihvonen et al. (2011) found these two informal groupings to be

769

770

771

772

773

774

775

776

777

778

779

780

781

782

783

784

785

786

787

788

789

790

791

792

793

794

795

796

797 reciprocally monophyletic.

In our analyses, 653 species with up to 11 markers were sampled, with an emphasis on Neotropical taxa, which so far had been poorly represented in the molecular phylogenetic analyses. Our results recovered the division into two major subclades, a core set of ennomines in a well-supported clade, and a poorly supported larger clade that includes the "boarmiines" among four other lineages usually thought of as "ennomines". The traditional "ennomines" are thus not found to be monophyletic in our analyses, questioning the utility of such an informal name. Our phylogenetic hypothesis supports the validation of numerous tribes proposed previously, in addition to several unnamed clades. We validate 23 tribes (Forum Herbulot, 2007; Skou \& Sihvonen, 2015): Gonodontini, Gnophini, Odontoperini, Nacophorini, Ennomini, Campaeini, Alsophilini, Wilemaniini, Prosopolophini, Diptychini, Theriini, Plutodini, Palyadini, Hypochrosini, Apeirini, Epionini, Caberini, Macariini, Cassymini, Abraxini, Eutoeini and Boarmiini. We hereby propose one new tribe: Drepanogynini trib. nov. (Table 2). Except for the new tribe, most of the groups recovered in this study are in concordance with previous morphological classifications (Holloway, 1993; Beljaev, 2006, 2016; Forum Herbulot, 2007; Skou \& Sihvonen, 2015).

Five known tribes and two further unnamed lineages (E1, E2 in figure 6) form the core Ennominae: Gonodontini, Gnophini, Odontoperini, Nacophorini and Ennomini. Several Neotropical clades that conflict with the current tribal classification of Ennominae will be described as new tribes by Brehm et al. (submitted). Gonodontini and Gnophini are recovered as sister taxa. Gonodontini was defined by Forbes (1948) and studied by Holloway (1994), who showed synapomorphies shared by Gonodontis Hübner, [1823], Xylinophylla Warren, 1898 and Xenimpia Warren, 1895. Our results recovered the genus Xylinophylla as sister of Xenimpia and Psilocladia Warren, 1898. Psilocladia is an African genus currently unassigned to tribe (see Sihvonen et al., 2015 for details). Considering the strong support and that the facies and morphology are somewhat similar to other analysed taxa in Gonodontini, we formally include Psilocladia in Gonodontini (Table 2). Gnophini are monophyletic and we formally transfer the African genera Oedicentra Warren, 1902 and Hypotephrina Janse, 1932, from unassigned to Gnophini (Table 2). The total number of species, and number of included genera in Gnophini are 
798 still uncertain (Skou \& Sihvonen, 2015). Based on morphological examination, Beljaev (2007,

799 2016) treated Angeronini as a synonym of Gnophini. The costal projection on male valva bearing

800 a spine or group of spines was considered as a synapomorphy of the group. Using molecular

801 data, Yamamoto \& Sota (2007) showed a close phylogenetic relationship between Angerona

802 Duponchel, 1829 (Angeronini) and Chariaspilates Wehrli, 1953 (Gnophini). Similar results were

803 shown by Sihvonen et al. (2011) who recovered Angerona and Charissa Curtis, 1826 as sister

804 taxa, and our results also strongly support treating Angeronini as synonym of Gnophini.

$805 \quad$ Holloway (1993) suggested close affinities among Nacophorini, Azelinini and

806 Odontoperini on the basis of larval characters. In a morphology-based phylogenetic study, Skou

807 \& Sihvonen (2015) suggested multiple setae on the proleg on A6 of the larvae as a

808 synapomorphy of the group. Our results also support a close relationship of Nacophorini,

809 Azelinini and Odontoperini. These clades will be treated in more detail by Brehm et al.

810 (submitted).

811 Following the ideas of Pitkin (2002), Beljaev (2008) synonymized the tribes

812 Ourapterygini and Nephodiini with Ennomini. He considered the divided vinculum in male

813 genitalia and the attachment of muscles $m 3$ as apomorphies of the Ennomini, but did not provide

814 a phylogenetic analysis. Sihvonen et al. (2011) supported Beljaev's assumptions and recovered

815 Ennomos Treitschke, 1825 (Ennomini), Ourapteryx Leach, 1814 (Ourapterygini) and Nephodia

816 Hübner, [1823] (Nephodiini) as belonging to the same clade. Our comprehensive analysis

817 confirms those previous findings and we agree with Ennomini as the valid tribal name for this

818 large clade.

819 Campaeini, Alsophilini, Wilemaniini and Prosopolophini grouped together in a well820 supported clade $(\mathrm{SH}-\mathrm{like}=100, \mathrm{UFBoot} 2=99)$. Previous molecular analyses have shown an 821 association of Colotoini [= Prosopolophini] and Wilemaniini (Yamamoto \& Sota, 2007;

822 Sihvonen et al., 2011), although no synapomorphies are known to support synonymization (Skou 823 \& Sihvonen, 2015). The Palaearctic genera Compsoptera Blanchard, 1845, Apochima Agassiz, 824 1847, Dasycorsa Prout, 1915, Chondrosoma Anker, 1854 and Dorsispina Nupponen \& 825 Sihvonen, 2013, are potentially part of the same complex (Skou \& Sihvonen, 2015, Sihvonen 826 pers. obs.), but they were not included in the current study. Campaeini is a small group including 
827 four genera with Oriental, Palaearctic and Nearctic distribution, apparently closely related to

828 Alsophilini and Prosopolophini, but currently accepted as a tribe (Forum Herbulot, 2007;

829 Sihvonen \& Skou, 2015). Our results support the close phylogenetic affinities among these

830 tribes, but due to the limited number of sampled taxa, we do not propose any formal changes.

831 The genus Declana Walker, 1858 is recovered as an isolated clade sister to Diptychini.

832 This genus is endemic to New Zealand, but to date has not been assigned to tribe. According to

833 our results, Declana could well be defined as its own tribe. However, the delimitation of this

834 tribe is beyond the scope of our paper and more genera from Australia and New Zealand should

835 first be examined. A close relationship between Nacophorini and Lithinini was suggested by

836 Pitkin (2002), based on the similar pair of processes of the anellus in the male genitalia. Pitkin

837 also noted a morphological similarity in the male genitalia (processes of the juxta) shared by

838 Nacophorini and Diptychini. In a study of the Australasian fauna, Young (2008) suggested the

839 synonymization of Nacophorini and Lithinini. This was further corroborated by Sihvonen et al.

840 (2015) who found that Diptychini were nested within some Nacophorini and Lithinini. However,

841 none of the studies proposed formal taxonomic changes because of limited taxon sampling. In

842 contrast, samples in our analyses cover all biogeographic regions and the results suggest that true

843 Nacophorini is a clade which comprises almost exclusively New World species. This clade is

844 clearly separate from Old World "nacophorines" (cf. Young, 2003) that are intermixed with

845 Lithinini and Diptychini. We here formally transfer Old World nacophorines to Diptychini and

846 synonymize Lithinini syn. nov. with Diptychini (Table 2). Further formal taxonomic changes in

847 the Nacophorini complex are provided by Brehm et al. (submitted).

848 Theria Hübner, [1825], the only representative of Theriini in this study, clustered

849 together with Lomographa Hübner, [1825] (Baptini in Skou \& Sihvonen, 2015), in a well-

850 supported clade, agreeing with the molecular results of Sihvonen et al. (2011). The placement of

851 Lomographa in Caberini (Rindge, 1979; Pitkin, 2002) is not supported by our study nor by that

852 of Sihvonen et al. (2011). The monophyly of Lomographa has not been tested before, but we

853 show that one Neotropical and one Palaearctic Lomographa species indeed group together. Our

854 results show that Caberini are not closely related to the Theriini + Baptini clade, unlike in earlier

855 morphology-based hypotheses (Rindge, 1979; Pitkin 2002). Morphologically, Theriini and 
856 Baptini are dissimilar, therefore we recognize them as valid tribes (see description and

857 illustrations in Skou \& Sihvonen, 2015).

858 According to our results, 11 molecular markers were not enough to infer phylogenetic

859 affinities of Plutodini (represented by one species of Plutodes). Similar results were found by

860 Sihvonen et al. (2011), who in some analyses recovered Plutodes as sister of Eumelea. Our

861 analyses are congruent with those findings. IQ-TREE results suggest that Plutodes is sister to

862 Palyadini, but RAxML analyses recovered Eumelea as the most probable sister of Plutodes.

863 Given that our analyses are not in agreement on the sister-group affinities of Plutodes, we do not

864 make any assumptions about its phylogenetic position. Instead we emphasize that further work

865 needs to be done to clarify the phylogenetic positions of Plutodes and related groups.

866 Hypochrosini is only recovered in a well-defined lineage if the genera Apeira Gistl, 1848

867 (Apeirini), Epione Duponchel, 1829 (Epionini), Sericosema (Caberini), Ithysia (Theriini),

868 Capasa Walker, 1866 (unassigned) and Omizodes Warren, 1894 (unassigned) were transferred to

869 Hypochrosini. Skou \& Sihvonen (2015) already suggested a close association of Epionini,

870 Apeirini and Hypochrosini. We think that synonymising these tribes is desirable. However, due

871 to the limited number of sampled taxa we do not propose any formal changes until more data

872 becomes available. We do suggest, however, formal taxonomic changes for the genera Capasa

873 and Omizodes from unassigned to Hypochrosini (Table 2).

874 The southern African genus Drepanogynis is paraphyletic and has earlier been classified

875 as belonging in Ennomini, and later in Nacophorini (Krüger 2002). In our phylogeny, it is

876 intermixed with the genera Sphingomima Warren, 1899, and Thenopa Walker, 1855.

877 Hebdomophruda errans Prout, 1917 also clusters together with these taxa, apart from other

878 Hebdomophruda Warren, 1897 species, which suggests that this genus is polyphyletic. These

879 genera form a clade sister to the lineage that comprises several Hypochrosini species.

880 Considering that our analysis strongly supports this clade, we place Thenopa, Sphingomina and

881 Drepanogynis in a tribe of their own.

882

883 Drepanogynini Murillo-Ramos, Sihvonen \& Brehm new tribe

884 LSIDurn:lsid:zoobank.org:act:AA384988-009F-4175-B98C-6209C8868B93

885 Type genus: Drepanogynis Guenée, [1858]

886 
887 The African genera Thenopa, Sphingomima and Drepanogynis appear as a strongly supported 888 lineage (SH-like, UFBoot2 and RBS = 100). Krüger (1997, p. 259) proposed "Boarmiini and 889 related tribes as the most likely sister group" for Drepanogynis, whereas more recently

890 Drepanogynis was classified in the putative southern hemisphere Nacophorini (Krüger, 2014; 891 Sihvonen et al., 2015). In the current phylogeny, Drepanogynis is isolated from Nacophorini 892 sensu stricto and from other southern African genera that have earlier been considered to be 893 closely related to it (Krüger 2014 and references therein). The other southern African genera 894 appeared to belong to Diptychini in our study. The systematic position of Drepanogynis 895 tripartita (Warren, 1898) has earlier been analysed in a molecular study (Sihvonen et al., 2015).

896 The taxon grouped together with the Palaearctic species of the tribes Apeirini, Theriini, Epionini 897 and putative Hypochrosini. Sihvonen et al. (2015) noted that Argyrophora trofonia (Cramer, 898 [1779]) (representing Drepanogynis group III sensu Krüger, 1999) and Drepanogynis tripartita 899 (representing Drepanogynis group IV sensu Krüger, 2002) did not group together, but no formal 900 changes were proposed. Considering that the current analysis strongly supports the placement of 901 Drepanogynis and related genera in an independent lineage, and the aforementioned taxa in the

902 sister lineage (Apeirini, Theriini, Epionini and putative Hypochrosini) have been validated at 903 tribe-level, we place Drepanogynis and related genera in a tribe of their own. Material examined and taxa included: Drepanogynis mixtaria Guenée, [1858], D. tripartita, D. determinata (Walker, 1860), D. arcuifera Prout, 1934, D. arcuatilinea Krüger, 906 2002, D. cnephaeogramma (Prout, 1938), D. villaria (Felder \& Rogenhofer, 1875), "Sphingomima" discolucida Herbulot, 1995 (genus combination uncertain, see taxonomic notes below), Thenopa diversa Walker, 1855, "Hebdomophruda" errans Prout, 1917 (genus combination uncertain, see taxonomic notes below).

Taxonomic notes: We choose Drepanogynis Guenée, [1858] as the type genus for

911 Drepanogynini, although it is not the oldest valid name (ICZN Article 64), because extensive

912 literature has been published on Drepanogynis (Krüger 1997, 1998, 1999, 2014), but virtually

913 nothing exists on Thenopa, except the original descriptions of its constituent species. Current

914 results show the urgent need for more extensive phylogenetic studies within Drepanogynini.

915 Thenopa and Sphingomima are embedded within Drepanogynis, rendering it paraphyletic, but

916 our taxon coverage is too limited to propose formal changes in this species-rich group.

917 Drepanogynini, as defined here, are distributed in sub-Saharan Africa. Drepanogynis sensu 
918 Krüger $(1997,1998,1999,2014)$ includes over 150 species and it ranges from southern Africa to

919 Ethiopia (Krüger 2002, Vári et al. 2002), whereas the genera Sphingomima (10 species) and

920 Thenopa (4 species) occur in Central and West Africa (Scoble 1999). Sphingomima and Thenopa

921 are externally similar, so the recovered sister-group relationship in the current phylogeny

922 analysis was anticipated. In the current analysis, Hebdomophruda errans Prout, 1917 is isolated

923 from other analysed Hebdomophruda species (the others are included in Diptychini),

924 highlighting the need for additional research. Krüger $(1997,1998)$ classified the genus

925 Hebdomophruda into seven species groups on the basis of morphological characters, and $H$.

926 errans group is one of them (Krüger 1998). We do not describe a new genus for the taxon

927 errans, nor do we combine it with any genus in the Drepanogynini, highlighting its uncertain

928 taxonomic position (incertae sedis) pending more research. In the current analysis, Sphingomima

929 discolucida Herbulot, 1995 is transferred from unassigned tribus combination to Drepanogynini,

930 but as the type species of Sphingomima (S. heterodoxa Warren, 1899) was not analysed, we do

931 not transfer the entire genus Sphingomima into Drepanogynini. We highlight the uncertain

932 taxonomic position of the taxon discolucida, acknowledging that it may eventually be included

933 again in Sphingomima if the entire genus should be transferred to Drepanogynini.

934

935 Diagnosis: Drepanogynini can be diagnosed by the combination of DNA data with up to 11

936 genetic markers (exemplar Drepanogynis mixtaria Guenée, [1858]) ArgK (MK738841), COI

937 (MK739615), EF1a (MK739960), IDH (MK740862), MDH (MK741181), Nex9 (MK741630),

938 RpS5 (MK741991) and Wingless (MK742540). In the light of our phylogenetic results, the

939 Drepanogynis group of genera, as classified earlier (Krüger 2014), is split between two unrelated

940 tribes (Drepanogynini and Diptychini). More research is needed to understand how other

941 Drepanogynis species and the Drepanogynis group of genera sensu Krüger (1997, 1998, 1999,

942 2014) (at least 11 genera), should be classified.

943 Boarmiini are the sister group to a clade that comprises Macariini, Cassymini, Abraxini

944 and Eutoeini. We found that many species currently assigned to Boarmiini are scattered

945 throughout Ennominae. Boarmiini s. str. are strongly supported but are technically not

946 monophyletic because of a large number of genera which need to be formally transferred from

947 other tribes to Boarmiini (see Brehm et al., submitted for Neotropical taxa and Murillo-Ramos et 
948 al., in prep. for other taxa). The results are principally in concordance with Jiang et al. (2017),

949 who supported the monophyly of Boarmiini but with a smaller number of taxa.

950 The divided valva in male genitalia was suggested as a synapomorphy of Macariini +

951 Cassymini + Eutoeini by Holloway (1994). In addition, he proposed the inclusion of Abraxini in

952 Cassymini. Although our findings support a close relationship, this group requires more study

953 and a more extensive sampling effort. Similar findings were provided by Jiang et al. (2017) who

954 suggested more extensive sampling to study the evolutionary relationships of these tribes.

955

956 Orthostixinae Meyrick, 1892

957 Orthostixinae were not included in our study. Sihvonen et al. (2011) showed this

958 subfamily as deeply embedded within Ennominae, but unfortunately it was not represented by

959 the type genus of the tribe. These results agree with Holloway (1996) who examined Orthostixis

960 Hübner, [1823] and suggested the inclusion in Ennominae despite the full development of

961 hindwing vein M2, the presence of a forewing areole and the very broad base of the tympanal

962 ansa. We sampled the species Naxa textilis (Preyer, 1884) and Orthostixis cribraria (Hübner,

963 1796), but only three and one marker were successfully sequenced for these samples,

964 respectively. We included these species in the preliminary analyses but results were so unstable

965 that we excluded them from the final analysis. Further research including fresh material and

966 more genetic markers are needed to investigate the position of Orthostixinae conclusively.

967

968 Conclusions

969 This study elucidated important evolutionary relationships among major groups within

970 Geometridae. The monophyly of the subfamilies and the most widely accepted tribes were

971 tested. We found strong support for the traditional concepts of Larentiinae, Geometrinae and

972 Ennominae. Sterrhinae also becomes monophyletic when Ergavia, Ametris and Macrotes,

973 currently placed in Oenochrominae, are formally transferred to Sterrhinae. The concepts of

974 Oenochrominae and Desmobathrinae required major revision and, after appropriate

975 rearrangements, these groups also form monophyletic subfamily-level entities. Archiearinae are

976 monophyletic with the transfer of Dirce and Acalyphes to Ennominae. We treat Epidesmiinae as

977 a new subfamily. 
978

979

980

981

982

983

984

985

986

987

988

989

990

991

992

993

994

995

996

997

998

999

1000

1001

1002

1003

1004

1005

1006

1007

This study proposes the recognition of eight monophyletic geometrid subfamilies. Many geometrid tribes were recovered para- or polyphyletic. We attempted to address the needed taxonomic changes, in order to favor taxonomic stability of the subfamilies and many tribes, even if in an interim way, to allow other researchers to use an updated higher-taxonomic structure that better reflects our current understanding of geometrid phylogeny. Although we included a large number of new taxa, in our study, many clades remain poorly represented. This is particularly true for taxa from tropical Africa and Asia. tribes in special need of reassessment include Eumeleini, Plutodini, Eutoeini, Cassymini and Abraxini. We hope the phylogenetic hypotheses shared here will open new paths of inquiry across Geometridae. Morphological synapomorphies have not yet been identified for many of the re- and newly defined higher taxa circumscribed by our 11-gene data set. Likewise, there is great need, across the family, to begin the work of mapping behavioral and life history attributes to the clades identified in this work.

\section{Acknowledgements}

Harri Sihvonen (Finland) is thanked for preparing extensive African materials for the study. We are grateful to Cathy Byrne (Hobart, Australia), B.C. Schmidt (Canada, Ottawa), Alfred Moser (Curitiba, Brazil), Rolf Mörtter (Karlsruhe, Germany), Daniel Bolt (Domat /Ems, Switzerland), Florian Bodner (Vienna, Austria), Dominik Rabl (Vienna, Austria), Aare Lindt (Tallinn, Estonia), Luis Parra (Concepción, Chile), Andreas Kopp (St. Margarethen, Switzerland), Stefan Naumann (Berlin, Germany), Jaan Viidalepp (Tartu, Estonia) for providing samples for this study. We thank John Chainey, Geoff Martin and Linda Pitkin at the NHM (London) for providing access to the collections and photographs of Neotropical Ennominae moths. We thank David Wagner, Andreas Zwick and Kevin Keegan for constructive comments on the manuscript.

\section{References}

Abraham D, Ryrholm N, Wittzell H, Jeremy DH, Scoble MJ, Löfstedt C. 2001. Molecular phylogeny of the subfamilies in Geometridae (Geometroidea: Lepidoptera). Molecular Phylogenetics and Evolution 20: 65-77.

Ban X, Jiang N, Cheng R, Xue D, Han H. 2018. Tribal classification and phylogeny of Geometrinae (Lepidoptera: Geometridae) inferred from seven gene regions. Zoological Journal of the Linnean Society, 184: 653-672 DOI: 10.1093/zoolinnean/zly013. 
1008 Beccaloni G Scoble M, Kitching I, Simonsen T, Robinson G, Pitkin B, Hine A, Lyal C.

1009

1010

1011

1012

1013

1014

1015

1016

1017

1018

1019

1020

1021

1022

1023

1024

1025

1026

1027

1028

1029

1030

1031

1032

1033 2003. "Subfamily Oenochrominae" The Global Lepidoptera Names Index. Natural History Museum, London. Available at http:/www.nhm.ac.uk/our-science/data/lepindex/ (accessed 3 August 2018).

Beljaev EA. 2006. A morphological approach to the Ennominae phylogeny (Lepidoptera, Geometridae). Spixiana 29: 215-216.

Beljaev EA. 2007. Tentative tribal system of Ennominae based on current family group names. Personal communication (not peer-reviewed), available at http://www.herbulot.de/pdf/Family_group_names_in_Geometridae_alternative_12_06_2 007.pdf (accessed 3 August 2018).

Beljaev EA. 2008. A new concept of the generic composition of the geometrid moth tribe Ennomini (Lepidoptera, Geometridae) Based on Functional Morphology of the Male Genitalia. Entomological Review 88: 50-60.

Brehm G, Hebert PDN, Colwell RK Adams MO, Bodner F, Friedemann K, Möckel L,Fiedler K. 2016. Turning up the heat at a hotspot: DNA barcodes reveal $80 \%$ more species of geometrid moths along an Andean elevational gradient. PlosOne 11: e0150327 DOI: 10.1371/journal.pone.0150327

Cook MA, Scoble MJ. 1992. Tympanal organs of geometrid moths: a review of their morphology, function, and systematic importance. Systematic Entomology 17: 219-232.

Forbes WTM. 1948. Lepidoptera of New York and neighboring states. II. Memoirs of the Cornell University Agricultural Experiment Station 274: 1-263.

Forum Herbulot. 2007. World list of family-group names in Geometridae. Available at http://www.herbulot.de/famgroup.htm (accessed 3 August 2018).

Guindon S, Dufayard JF, Lefort V, Anisimova M, Hordijk W, Gascuel O. 2010. New algorithms and methods to estimate maximum-likelihood phylogenies: assessing the performance of PhyML 3.0. Systematic Biology 59: 307-321.

Peer] reviewing PDF | (2019:01:34676:2:0:NEW 11 Jun 2019) 
1034 Hausmann A. 2001. Geometrid moths of Europe. Vol. 1: introduction to the series. Archiearinae, Oenochrominae, Geometrinae. Apollo books, Stenstrup.

1036

Hausmann A. 2004 Geometrid moths of Europe. Vol. 2: Sterrhinae. Apollo books, Stenstrup.

1037

1038

1039

1040

1041

1042

1043

1044

1045

1046

1047

1048

1049

1050

1051

1052

1053

1054

1055

1056

1057

1058

Hausmann A, Hebert PDN, Mitchell A, Rougerie R, Sommerer M, Edwards T, Young K. 2009. Revision of the Australian Oenochroma vinaria Guenée, 1858 species-complex (Lepidoptera: Geometridae, Oenochrominae): DNA barcoding reveals cryptic diversity and assesses status of type specimen without dissection. Zootaxa 2239: 1-21.

Hausmann A, Viidalepp J. 2012. Geometrid moths of Europe. Vol. 3: Larentiinae I. Apollo books, Stenstrup.

Heikkilä M, Mutanen M, Wahlberg N, Sihvonen P, Kaila L. 2015. Elusive ditrysian phylogeny: an account of combining systematized morphology with molecular data (Lepidoptera). BMC Evolutionary Biology 15: 1-27 DOI: 10.1186/s12862-015-0520-0.

Hoang DT, Chernomor O, Haeseler A, Minh BQ, Vinh LS. 2018. UFBoot2: Improving the ultrafast bootstrap approximation. Molecular Biology and Evolution 35: 518-522 DOI: 10.1093/molbev/msx281.

Holloway J. 1994. The moths of Borneo, part 11: Family Geometridae, subfamily Ennominae. Malayan Nature Journal 47: 1-309.

Holloway J. 1996. The moths of Borneo, part 9: Geometridae (incl. Orthostixini), Oenochrominae, Desmobathrinae, Geometrinae, Ennominae. Malayan Nature Journal 49: $147-326$.

Holloway J. 1997. The moths of Borneo, part 10: family Geometridae, subfamilies Sterrhinae and Larentiinae. Malayan Nature Journal 51: 1-242.

Inoue H. 1961. Lepidoptera: Geometridae. Insecta Japonica 4: 1-106.

International Commission on Zoological Nomenclature 2012: International Code of Zoological Nomenclature, fourth edition. Available online http://iczn.org/iczn/index.jsp 
1059 Jiang N, Li XX, Hausmann A, Cheng R, Xue DY, Han HX. 2017. A molecular phylogeny of the 1060 Palaearctic and Oriental members of the tribe Boarmiini (Lepidoptera: Geometridae: $1061 \quad$ Ennominae). Invertebrate Systematics 31: 427-441.

1062 Kalyaanamoorthy S, Minh BQ, Wong TKF, Haeseler A von, Jermiin LS. 2017. ModelFinder:

1063 Fast Model Selection for Accurate Phylogenetic Estimates Nature Methods 14: 587-589 DOI: $10.1038 /$ nmeth.4285.

1065

1066 1067

1068

1069

1070

1071

1072

1073

1074

1075

1076

1077

1078

1079

1080

1081

1082

1083

1084

1085

1086

Krüger M. 1997. Revision of Afrotropical Ennominae of the Drepanogynis group I: the genus Hebdomophruda Warren, Part 1. Annals of the Transvaal Museum 36: 257-291.

Krüger M. 1998. Revision of Afrotropical Ennominae of the Drepanogynis group II: the genus Hebdomophruda Warren, Part 2. Annals of the Transvaal Museum 36: 333-349.

Krüger M. 1999. Revision of Afrotropical Ennominae of the Drepanogynis group III: the genera Argyrophora Guenée, Pseudomaenas Prout and Microligia Warren. Annals of the Transvaal Museum 36: 427-496.

Krüger M. 2002. Revision of Afrotropical Ennominae of the Drepanogynis group IV: the genus Drepanogynis Guenée (Lepidoptera: Geometridae). Transvaal Museum Monograph 13: $1-220$ incl. 442 figs.

Krüger M. 2014: A revision of the Mauna Walker, 1865 and Illa Warren, 1914 group of genera (Lepidoptera: Geometridae: Ennominae: Nacophorini). Annals of the Ditsong National Museum of Natural History 4: 77-173.

Lanfear R, Calcott B, Ho SYW, Guindon S. 2012. Partitionfinder: Combined selection of partitioning schemes and substitution models for phylogenetic analyses. Molecular Biology and Evolution 29: 1695-1701 DOI:10.1093/molbev/mss020 pmid:22319168.

Meyrick E. 1889. Revision of Australian Lepidoptera. Proceedings of the Linnean Society of New South Wales 41: 117-1216. 
1087 Miller MA, Pfeiffer W, Schwartz T. 2010. Creating the CIPRES science gateway for inference of 1088 large phylogenetic trees. In Proceedings of the Gateway Computing Environments Workshop (GCE), New Orleans, LA pp 1 - 8. Available at http://www.phylo.org. (accessed June, 2018).

1091

1092

1093

Minet J, Scoble MJ.1999. The Drepanoid/Geometroid assemblage. In: Kristensen NP, ed. Handbook of Zoology, part 35, Lepidoptera, Moths and Butterflies, Vol. 1, Evolution, Systematics, and Biogeography: De Gruyter, Berlin, 301-320.

Mironov V. 2003. Larentiinae II (Perizomini and Eupitheciini). In: Hausmann A, ed. The Geometrid Moths of Europe 4. Apollo Books, Stenstrup, 1-463.

Nguyen LT, Schmidt HA, Haeseler A von, Minh BQ. 2015. IQ- TREE: A fast and effective stochastic algorithm for estimating maximum likelihood phylogenies. Molecular Biology and Evolution 32: 268-274 DOI: 10.1093/molbev/msu300.

Nieukerken EJ van, Kaila L, Kitching IJ, Kristensen NP, Lees DC, Minet J, Mitter C, Mutanen M, Regier JC, Simonsen TJ, Wahlberg N, Yen S, Zahiri R, Adamski D, Baixeras J, Bartsch D, Bengtsson BÅ, Brown JW, Bucheli SR, Davis DR, Prins J de, Prins W de, Epstein ME, Gentili-Poole P, Gielis C, Hättenschwiler P, Hausmann A, Holloway JD, Kallies A, Karsholt O, Kawahara AY, Koster J, Kozlov M, Lafontaine JD, Lamas G, Landry J, Lee S, Nuss M, Park K, Penz C, Rota J, Schintlmeister A, Schmidt BC, Sohn J, Solis MA, Tarmann GM, Warren AD, Weller S, Yakovlev RV, Zolotuhin VV, Zwick A. 2011. Order Lepidoptera Linnaeus, 1758. In: Zhang, Z.-Q. (Ed.), Animal biodiversity: An outline of higher-level classification and survey of taxonomic richness. Zootaxa 3148: $212-221$.

Õunap E, Viidalepp J, Saarma U. 2008. Systematic position of Lythriini revised: transferred from Larentiinae to Sterrhinae (Lepidoptera, Geometridae). Zoologica Scripta 37: 405413.

Õunap E, Viidalepp J. 2009. Description of Crypsiphona tasmanica sp. nov. (Lepidoptera: Geometridae: Geometrinae), with notes on limitations in using DNA barcodes for delimiting species. Australian Journal of Entomology 48: 113-124.

Peer] reviewing PDF | (2019:01:34676:2:0:NEW 11 Jun 2019) 
1115 Õunap E, Javoiš J, Viidalepp J , Tammaru T . 2011. Phylogenetic relationships of selected

1116

1117

1118

1119

1120

1121

1122

1123

1124

1125

1126

1127

1128

1129

1130

1131

1132

1133

1134

1135

1136

1137

1138

1139

European Ennominae (Lepidoptera: Geometridae). European Journal of Entomology 108: 267-273.

Õunap E, Viidalepp J, Truuverk A. 2016. Phylogeny of the subfamily Larentiinae (Lepidoptera: Geometridae): integrating molecular data and traditional classifications. Systematic Entomology 21: 824-843 DOI:10.1111/syen.12195.

Peña C, Malm T. 2012. VoSeq: a voucher and DNA sequence web application. PLoS ONE 7: e39071.

Pitkin L. 1996. Neotropical emerald moths: a review of the genera (Lepidoptera: Geometridae, Geometrinae). Zoological Journal of the Linnean Society 118: 309-440.

Pitkin L. 2002. Neotropical Ennomine moths: a review of the genera (Lepidoptera: Geometridae). Zoological Journal of the Linnean Society 135: 121-401.

Pitkin B, Jenkins P. 2004. Butterflies and moths of the world, generic names and their typespecies. Available at http://www.nhm.ac.uk/our-science/data/butmoth/ (accessed 29 August, 2018).

Pitkin L, Han H, James S. 2007. Moths of the tribe Pseudoterpnini (Geometridae: Geometrinae): a review of the genera . Zoological Journal of the Linnean Society 150:343-412.

Rajaei H, Greve C, Letsch H, Stüning D, Wahlberg N, Minet J, Misof B. 2015. Advances in Geometroidea phylogeny, with characterization of a new family based on Pseudobiston pinratanai (Lepidoptera, Glossata). Zoologica Scripta 44: 418-436. DOI:10.1111/zsc. 12108 .

Rambaut A. 2012. Figtree 1.4.0. Available at http://tree.bio.ed.ac.uk/software/figtree/ (accessed 3 August 2018).

Ratnasingham S, Hebert PD. 2007. BOLD: the barcode of life data systems. Molecular Ecology Notes 7: 355-364 DOI:10.1111/j.1471-8286.2007.01678.x.

Peer) reviewing PDF | (2019:01:34676:2:0:NEW 11 Jun 2019) 
1140 Regier JC, Zwick A, Cummings MP, Kawahara AY, Cho S, Weller S, Roe A, Baixeras J, Brown

1141

1142

1143

1144

1145

1146

1147

1148

1149

1150

1151

1152

1153

1154

1155

1156

1157

1158

1159

1160

1161

1162

1163

1164 JW, Parr C, Davis DR, Epstein M, Hallwachs W, Hausmann A, Janzen DH, Kitching IJ, Solis MA, Yen SH, Bazinet AL, Mitter C. 2009. Toward reconstructing the evolution of advanced moths and butterflies (Lepidoptera: Ditrysia): an initial molecular study. BMC Evolutionary Biology 9: 280 DOI:10.1186/1471-2148-9-280.

Regier JC, Mitter C, Zwick A, Bazinet AL, Cummings MP, Kawahara AY, Sohn JC, Zwick1 DJ, Cho S, Davis DR, Baixeras J, Brown J., Parr C, Weller S, Lees DC, Mitter KT. 2013. A large-scale, higher-level, molecular phylogenetic study of the insect order Lepidoptera (moths and butterflies). PLoS ONE 8: e58568.

Rindge FH. 1979. A revision of the North American moths of the genus Lomographa (Lepidoptera, Geometridae). American Museum Novitates 2673: 118.

Rota J. 2011. Data partitioning in Bayesian analysis: molecular phylogenetics of metalmark moths (Lepidoptera: Choreutidae). Systematic Entomology 36: 317-329 DOI: 10.1111/j.1365-3113.2010.00563.x

Scoble MJ, Edwards ED.1990. Parepisparis Bethune-Baker and the composition of the Oenochrominae (Lepidoptera: Geometridae). Entomologica Scandinavica 20: 371-399.

Scoble MJ. 1992. Lepidoptera: Form Function and Diversity. Oxford: Oxford University Press.

Scoble, M.J. 1999. Geometrid Moths of theWorld: A catalogue (Lepidoptera, Geometridae). vols. 1 \& 2. Collingwood, CSIRO.

Sihvonen P, Kaila L. 2004. Phylogeny and tribal classification of Sterrhinae with emphasis on delimiting Scopulini (Lepidoptera: Geometridae). Systematic Entomology 29: 324-358.

Sihvonen P, Mutanen M, Kaila L, Brehm G, Hausmann A, Staude HS. 2011. Comprehensive molecular sampling yields a robust phylogeny for geometrid moths (Lepidoptera: Geometridae). PLoS ONE 6: e20356 DOI: doi:10.1371/journal.pone.0020356. 
1165 Sihvonen P, Staude H. 2011. Geometrid moth Afrophyla vethi (Snellen, 1886) transferred from Oenochrominae to Sterrhinae (Lepidoptera: Geometridae). Metamorphosis 22: 102-113.

1167 Sihvonen P, Staude HS, Mutanen M. 2015. Systematic position of the enigmatic African cycad 1168 moths: an integrative approach to a nearly century old problem (Lepidoptera: Geometridae, Diptychini). Systematic Entomology 40: 606-627.

Skou P, Sihvonen P. 2015. The Geometrid Moths Of Europe. Vol. 5: Ennominae I. Apollo books, Stenstrup.

Stamatakis A, Hoover P, Rougemont J. 2008. A rapid bootstrap algorithm for the RAxML Web servers, Systematic Biology 57: 758-771.

1174 Stamatakis, A. (2014) RAxML Version 8: A tool for Phylogenetic Analysis and Post-Analysis of Large Phylogenies. Bioinformatics 30 (9):13121313 DOI: 10.1093/bioinformatics/btu033.

1177 Staude HS. 2001. A revision of the genus Callioratis Felder (Lepidoptera: Geometridae: Diptychinae). Metamorphosis 12: 125-156.

1179 Staude H, Sihvonen P. 2014. Revision of the African geometrid genus Zerenopsis C. \&. R. Felder-moths with peculiar life histories and mating behaviors (Geometridae: Ennominae: Diptychini). Metamorphosis 25: 11-55.

1182 Strutzenberger P, Brehm G, Gottsberger B, Bodner F, Seifert, CL, Fiedler, K. 2017. Diversification rates, host plant shifts and an updated molecular phylogeny of Andean Eois moths (Lepidoptera: Geometridae). PlosOne 12: e018843 http://www.iqtree.org/doc/Frequently-Asked-Questions (accessed 13 August 2018). 
1191 Viidalepp J. 2006. Cladistic analysis of the subfamily Larentiinae. In: Hausmann A, McQuillan

1192 P, eds. Proceedings of the Forum Herbulot 2006. Integration of molecular, ecological and

1193 morphological data: Recent progress towards the higher classification of the Geometridae

1194 (Hobart, 19-20 January 2006). Spixiana 29: 202-203.

1195 Viidalepp J. 2011. A morphological review of tribes in Larentiinae (Lepidoptera: Geometridae).

1196 Zootaxa 3136: 1-44.

1197 Yamamoto S, Sota T. 2007. Phylogeny of the Geometridae and the evolution of winter moths 1198 inferred from a simultaneous analysis of mitochondrial and nuclear genes. Molecular $1199 \quad$ Phylogenetics and Evolution 44: 711-723.

1200 Young CJ. 2003. The Place of the Australian Nacophorini in the Geometridae. Spixiana 26: 1991201200.

1202 Young CJ. 2006. Molecular relationships of the Australian Ennominae (Lepidoptera: Geometridae) and implications for the phylogeny of the Geometridae from molecular and morphological data. Zootaxa 1264: 1-147.

Young CJ. 2008. Characterization of the Australian Nacophorini using adult morphology, and phylogeny of the Geometridae based on morphological characters. Zootaxa 1736: 1-141.

1207 Wahlberg N, Wheat CW. 2008. Genomic outposts serve the phylogenomic pioneers: designing novel nuclear markers for genomic DNA extractions of Lepidoptera. Systematic Biology 57: 231-242.

1210 Wahlberg N, Snäll N, Viidalepp J, Ruohomäki K, Tammaru T. 2010. The evolution of female flightlessness among Ennominae of the Holarctic forest zone (Lepidoptera, Geometridae). Molecular Phylogenetics and Evolution 55: 929-938.

1213 Wahlberg N., Peña, C., Ahola, M., Wheat C.W., Rota J. 2016. PCR primers for 30 novel gene 1214 regions in the nuclear genomes of Lepidoptera. ZooKeys 596: 129-141.

1215 https://doi.org/10.3897/zookeys.596.8399 
1217 
Figure 1 (on next page)

Evolutionary relationships in major groups of the family Geometridae.

Numbers above branches are SH-aLRT support (\%) / ultrafast bootstrap support, UFBoot2(\%), for nodes to the right of the numbers. Values of $\mathrm{SH}>=80$ and UFBoot2 $>=95$ indicate wellsupported clades (Trifinopoulos \& Minh, 2018). *Formal taxonomic treatment will be dealt with in Sihvonen et al. in prep. § Epidesmiinae subfam. nov. See Oenochrominae section for more details. 
Figure 2 (on next page)

Evolutionary relationships of the subfamily Sterrhinae.

Numbers above branches are SH-aLRT support (\%) / ultrafast bootstrap support, UFBoot2(\%), for nodes to the right of the numbers. Values of $\mathrm{SH}>=80$ and UFBoot2 $>=95$ indicate wellsupported clades (Trifinopoulos \& Minh, 2018). *Formal taxonomic treatment will be dealt with in Sihvonen et al. in prep. 


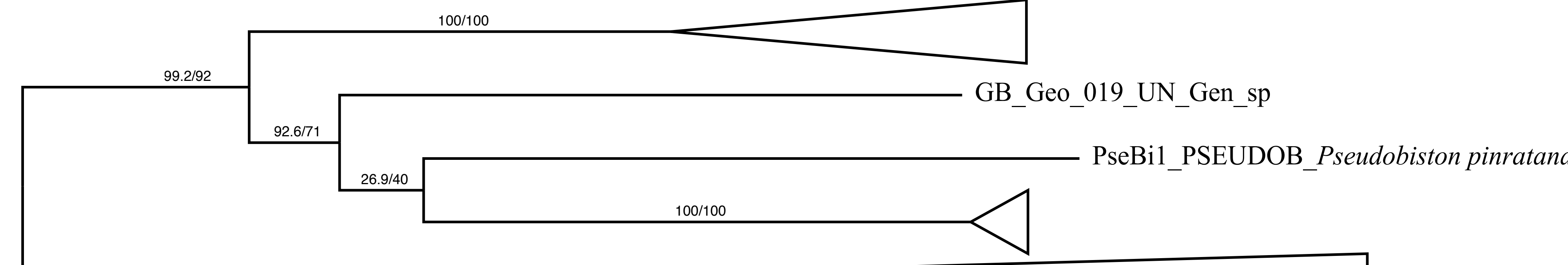

$98.7 / 97$

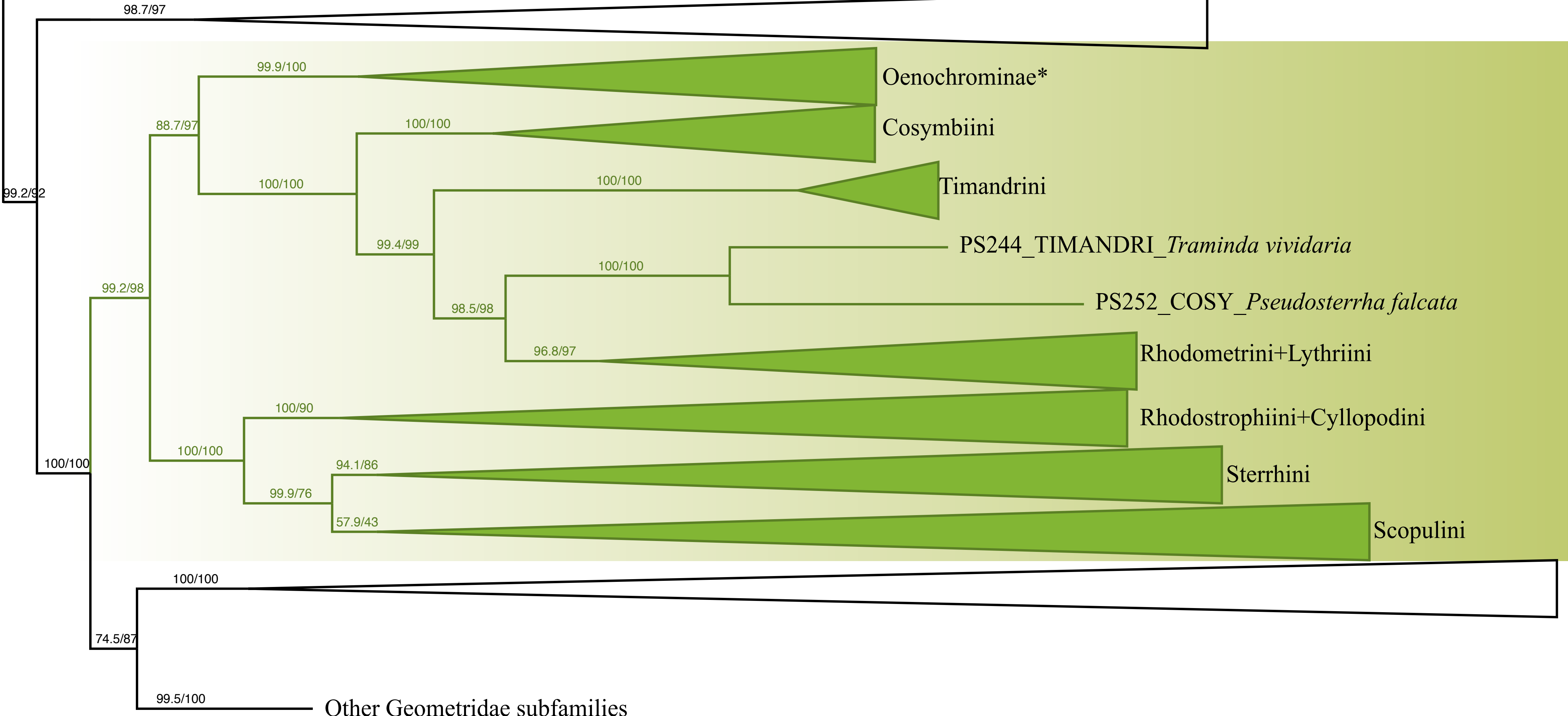

Sterrhinae+Oenochrominae*

Larentiinae

Archiearinae 
Figure 3 (on next page)

Evolutionary relationships of the subfamily Larentiinae.

Numbers above branches are SH-aLRT support (\%) / ultrafast bootstrap support, UFBoot2(\%), for nodes to the right of the numbers. Values of $\mathrm{SH}>=80$ and UFBoot2 $>=95$ indicate wellsupported clades (Trifinopoulos \& Minh, 2018). 


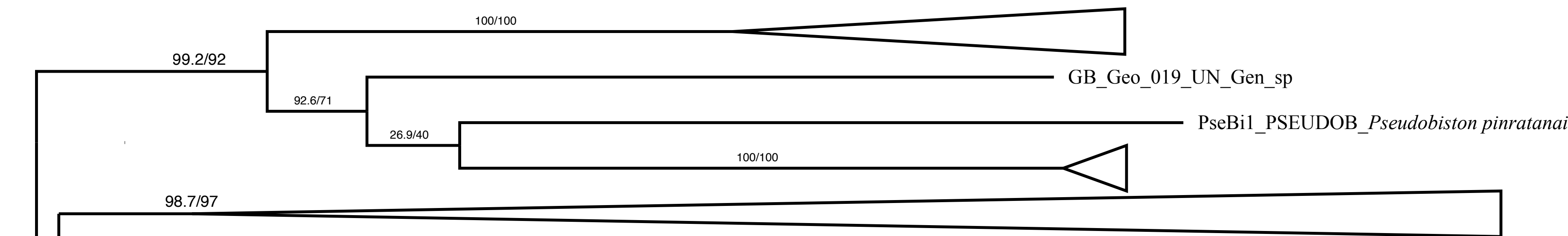

$-1$

$9.2 / 98$

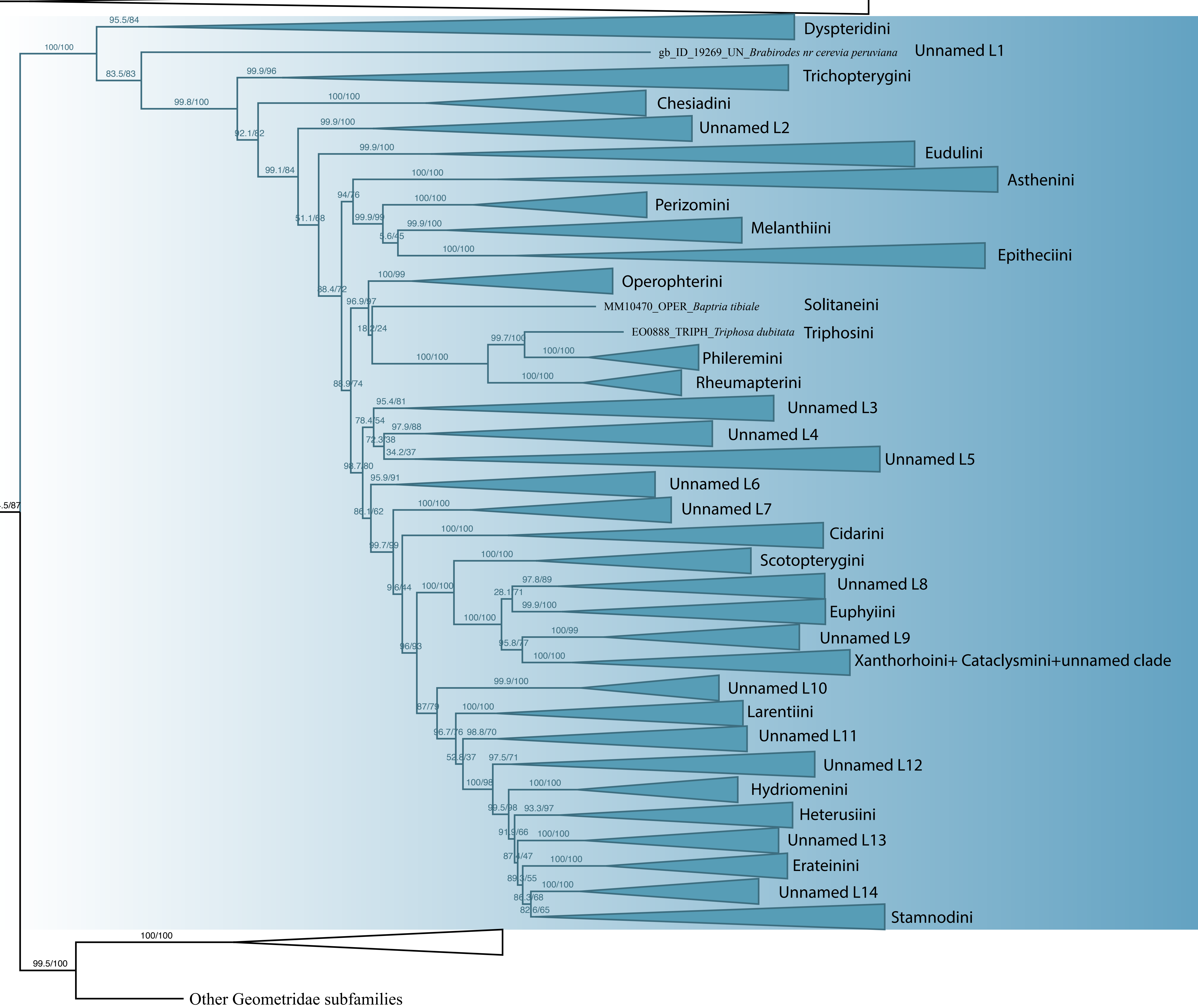

Sematuridae

Unnamed

Pseudobistonidae

Epicopeiidae

Uraniidae

Sterrhinae+Oenochrominae*

Larentiinae 
Figure 4 (on next page)

Phylogenetic relationships of the subfamilies Archierinae, Desmobathrinae, Epidesmiinae subfam. nov., Oenochrominae.

Numbers above branches are SH-aLRT support (\%) / ultrafast bootstrap support, UFBoot2(\%), for nodes to the right of the numbers. Values of $\mathrm{SH}>=80$ and UFBoot2>=95 indicate wellsupported clades (Trifinopoulos \& Minh, 2018). Taxonomic changes are indicated by a symobolized arrow $>$. 


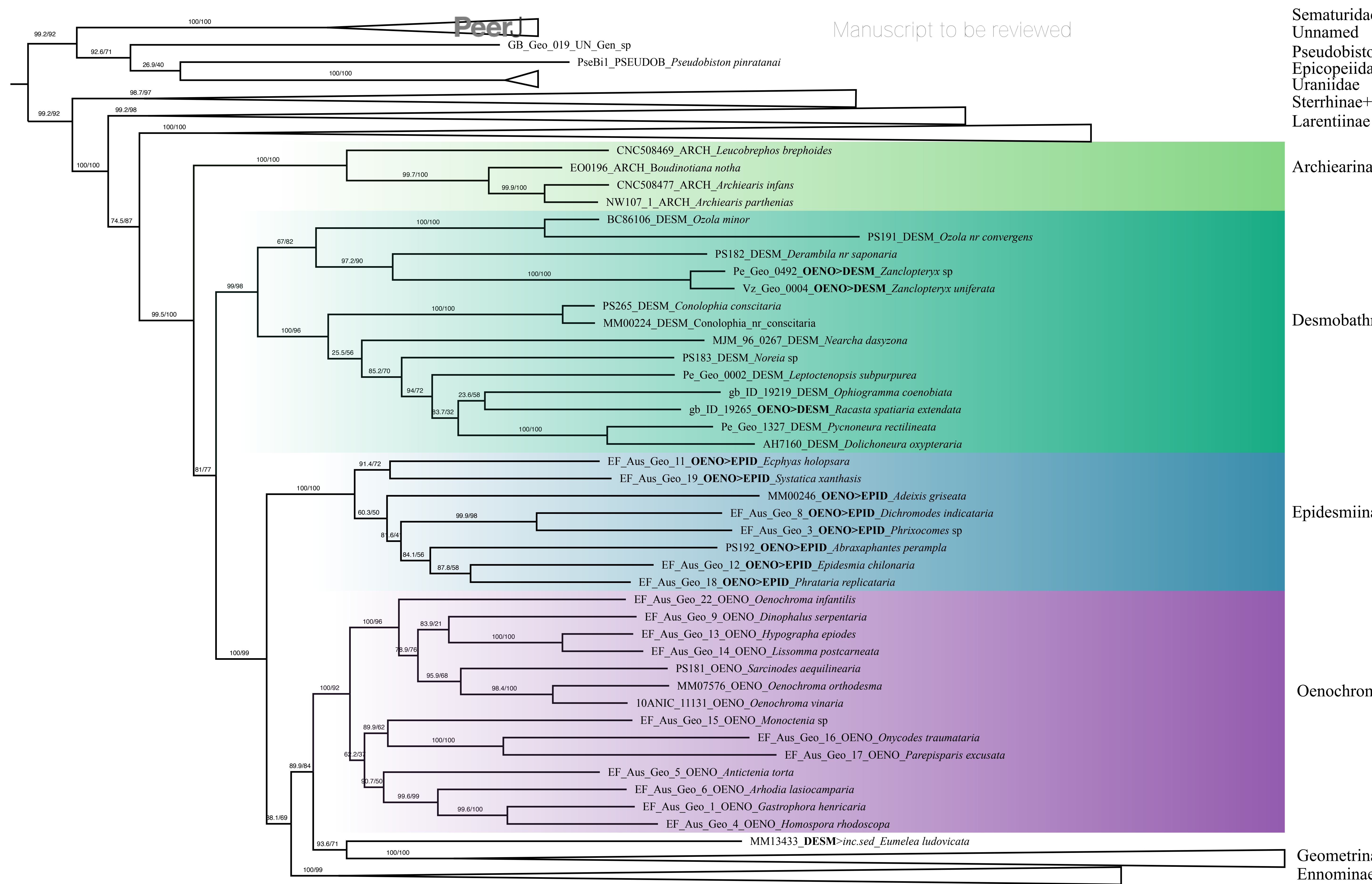

Sematuridae
Unnamed

Pseudobistonidae

Epicopeiidae
Uraniidae

Sterrhinae+Oenochrominae*

Larentiinae

Archiearinae

Desmobathrinae+Oenochrominae

Epidesmiinae §

Oenochrominae s.str 
Figure $\mathbf{5}$ (on next page)

Evolutionary relationships of the subfamily Geometrinae.

Numbers above branches are SH-aLRT support (\%) / ultrafast bootstrap support, UFBoot2(\%), for nodes to the right of the numbers. Values of $\mathrm{SH}>=80$ and UFBoot2 $>=95$ indicate wellsupported clades (Trifinopoulos \& Minh, 2018).Taxonomic changes are indicated by a symobolized arrow $>$. 
(1)

Agathiini

Chlorodontoperini trib.nov.

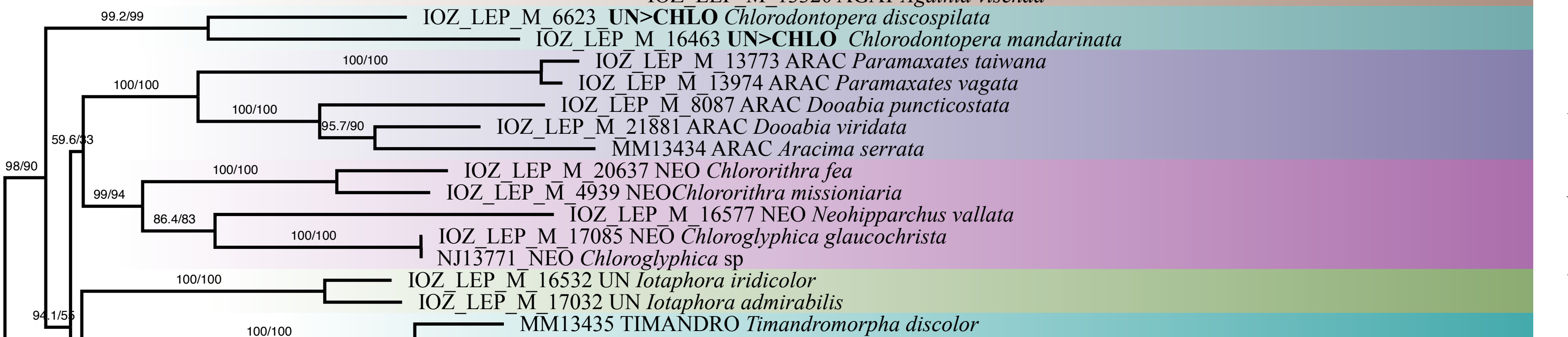

Aracimini

Neohipparchini

Unnamed G1

Timandromorphini

Geometrini

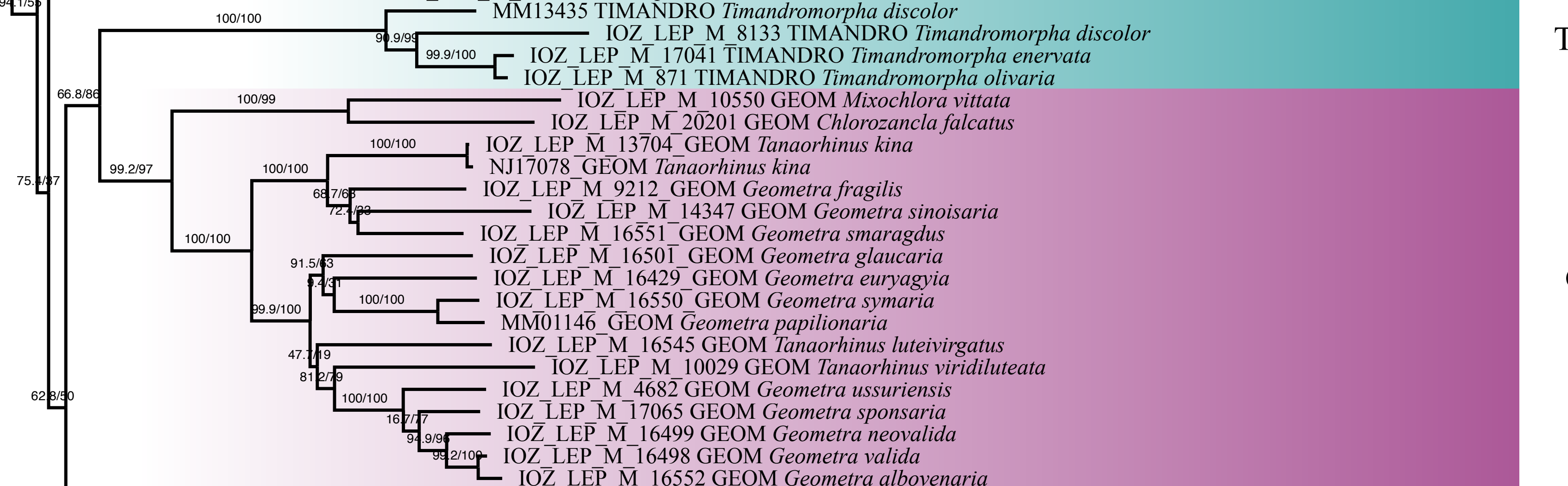

(1)

Ge

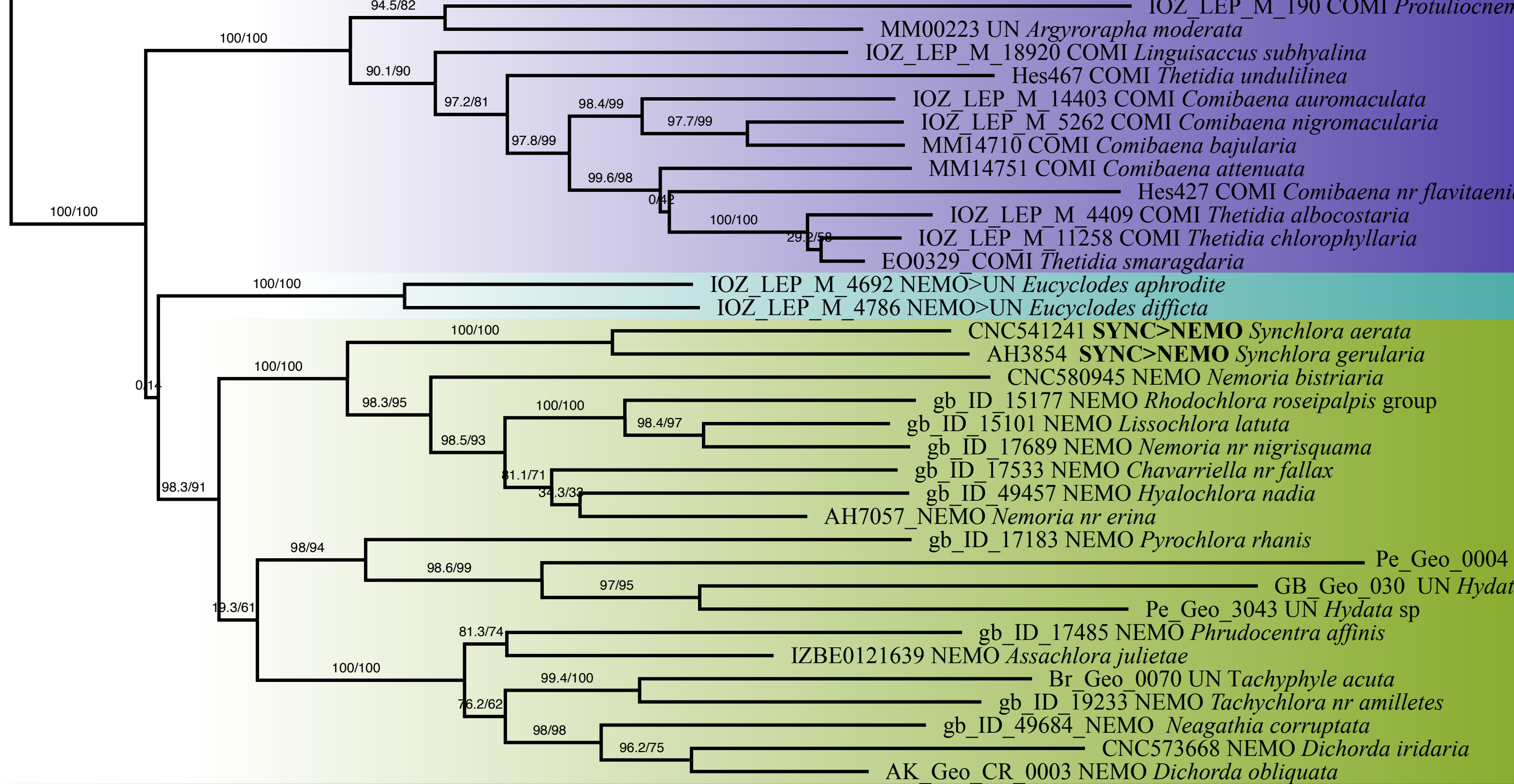

Comibaenini

Unnamed G2

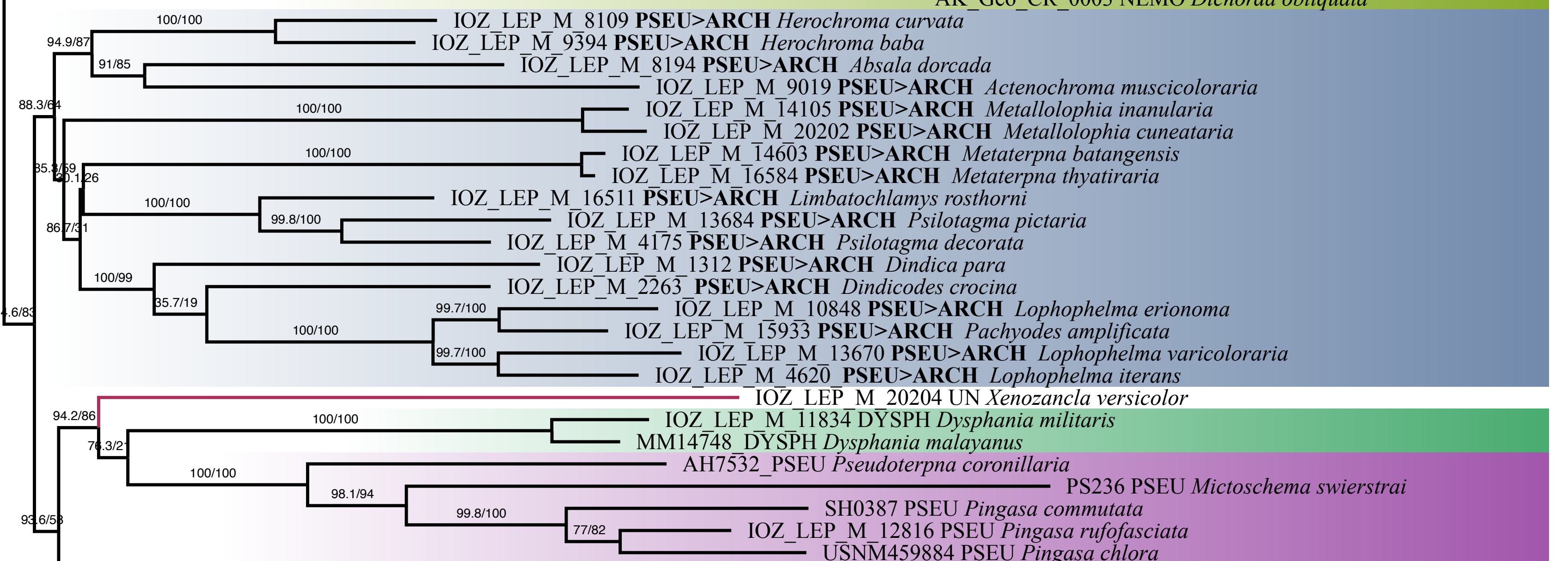

Archaeobalbini stat.rev.

Unnamed G3

Dysphaniini

Pseudoterpnini

Unnamed G4

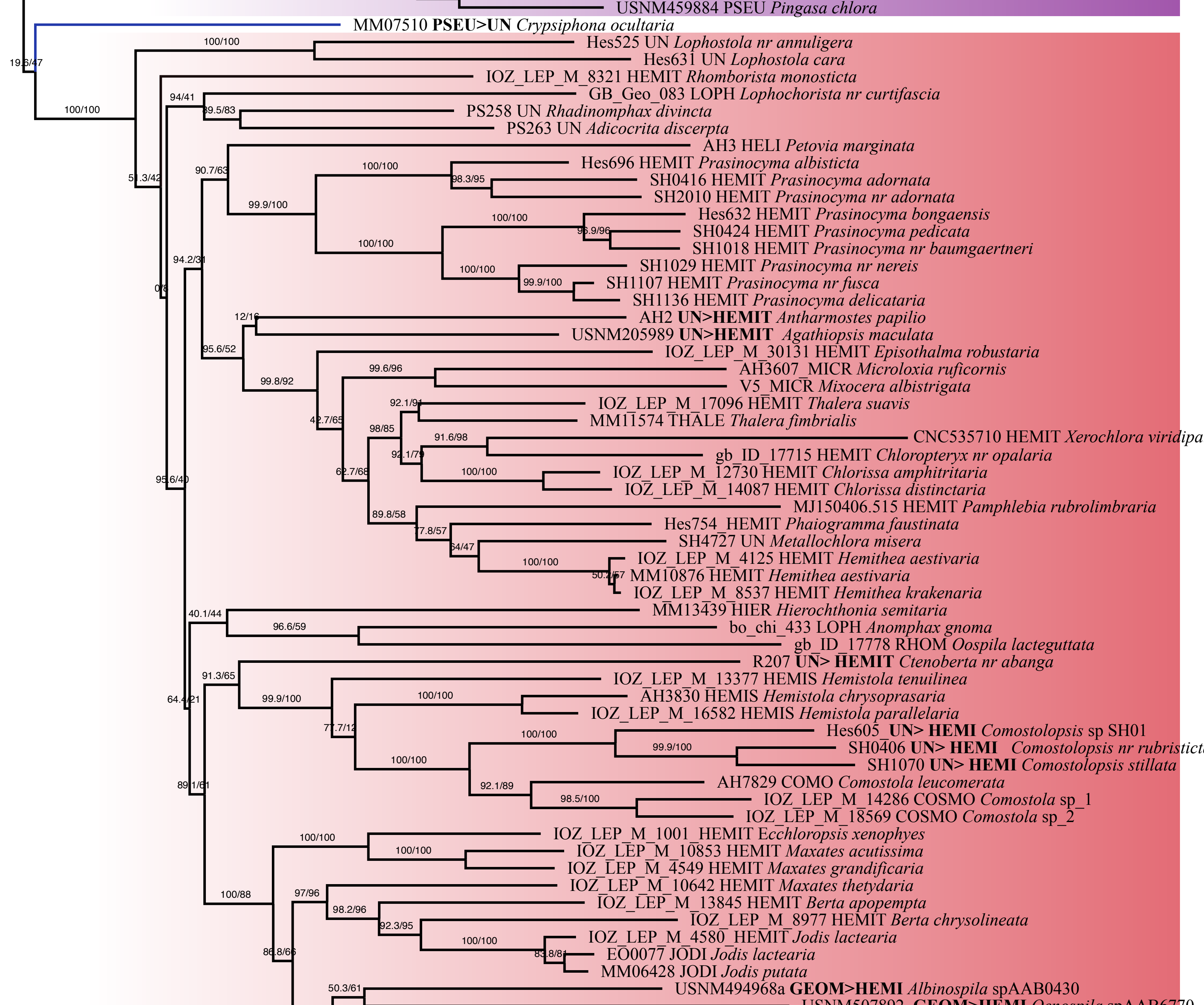

Hemitheini 
Figure 6 (on next page)

Evolutionary relationships of the subfamily Ennominae.

Numbers above branches are SH-aLRT support (\%) / ultrafast bootstrap support, UFBoot2(\%), for nodes to the right of the numbers. Values of $\mathrm{SH}>=80$ and UFBoot2 $>=95$ indicate wellsupported clades (Trifinopoulos \& Minh, 2018).Taxonomic changes are indicated by a symobolized arrow >.* Formal taxonomic treatment will be dealt with in Brehm et al. submitted. 


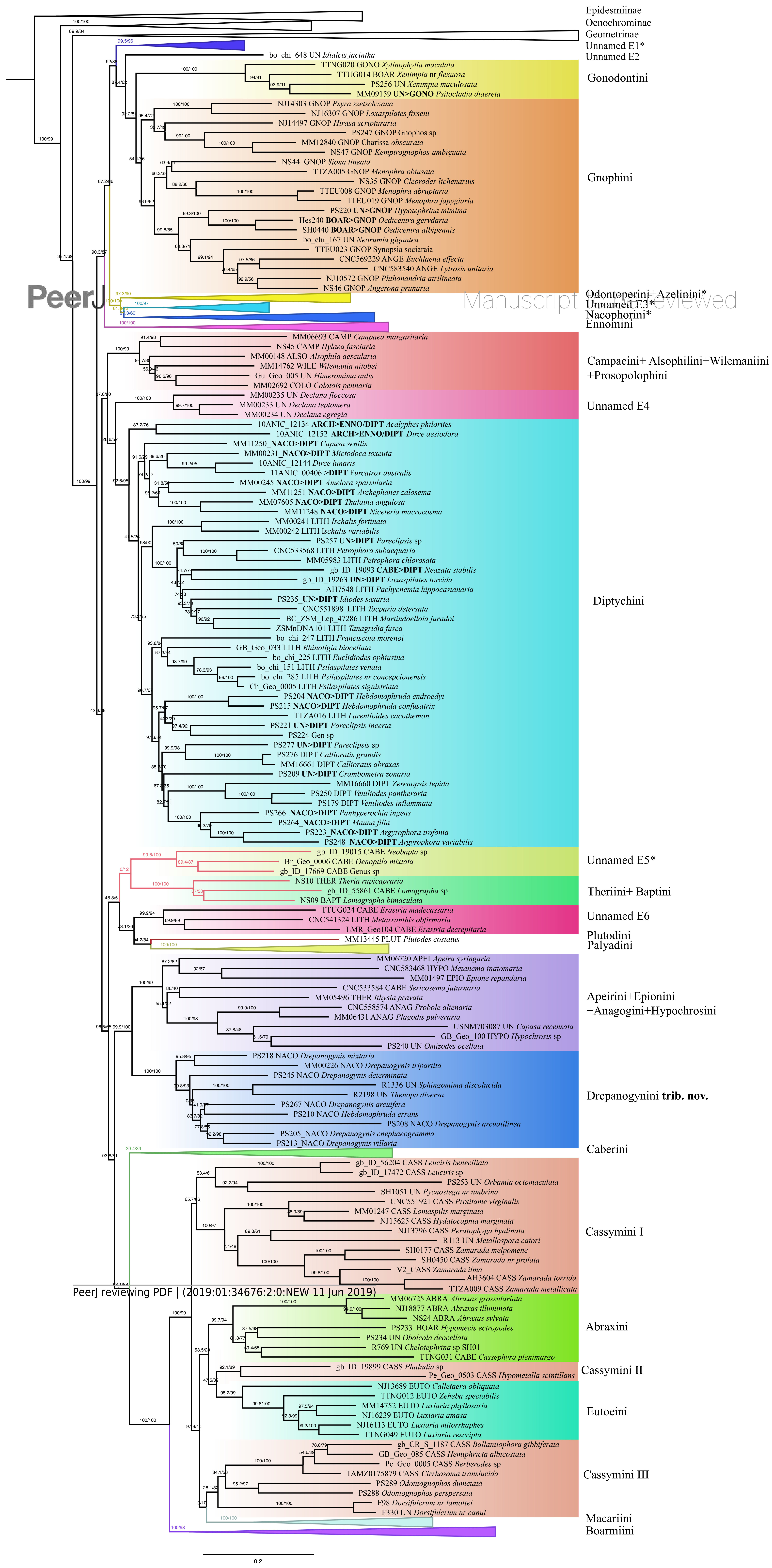




\section{Table $\mathbf{1}$ (on next page)}

Evolutionary models recovered in ModelFinder 


\begin{tabular}{|c|c|c|}
\hline $\begin{array}{l}\text { Evolutionary } \\
\text { models }\end{array}$ & Codon position & Data type \\
\hline SYM+R5 & ArgK_pos1 & Nuclear \\
\hline SYM+R4 & ArgK_pos2_Ca-ATPase_pos2 & Nuclear \\
\hline $\mathrm{GTR}+\mathrm{F}+\mathrm{R} 6$ & ArgK_pos3 & Nuclear \\
\hline $\mathrm{GTR}+\mathrm{F}+\mathrm{R} 5$ & Ca-ATPase_pos1_IDH_pos1 & Nuclear \\
\hline $\mathrm{SYM}+\mathrm{I}+\mathrm{G} 4$ & Ca-ATPase_pos3 & Nuclear \\
\hline $\mathrm{SYM}+\mathrm{I}+\mathrm{G} 4$ & CAD_pos1 & Nuclear \\
\hline $\mathrm{K} 3 \mathrm{P}+\mathrm{I}+\mathrm{G} 4$ & CAD_pos2 & Nuclear \\
\hline $\mathrm{GTR}+\mathrm{F}+\mathrm{R} 7$ & CAD_pos3 & Nuclear \\
\hline $\mathrm{TIM} 2+\mathrm{F}+\mathrm{I}+\mathrm{G} 4$ & COI_pos1 & Mitochondrial \\
\hline $\mathrm{K} 2 \mathrm{P}+\mathrm{R} 8$ & COI_pos2_MDH_pos2_RpS5_pos2_WntGeo_pos2 & Mitochondrial/Nuclear \\
\hline $\mathrm{GTR}+\mathrm{F}+\mathrm{ASC}+\mathrm{R} 10$ & COI_pos3 & Mitochondrial \\
\hline TIM2e+R10 & EF1a_pos1 & Nuclear \\
\hline $\mathrm{TIM}+\mathrm{F}+\mathrm{I}+\mathrm{G} 4$ & EF1a_pos2 & Nuclear \\
\hline SYM+R10 & EF1a_pos3_GAPDH_pos3_RpS5_pos3 & Nuclear \\
\hline $\mathrm{TVM}+\mathrm{F}+\mathrm{I}+\mathrm{G} 4$ & GAPDH_pos1 & Nuclear \\
\hline $\mathrm{SYM}+\mathrm{I}+\mathrm{G} 4$ & GAPDH_pos2 & Nuclear \\
\hline $\mathrm{GTR}+\mathrm{F}+\mathrm{R} 4$ & IDH_pos2 & Nuclear \\
\hline SYM+R6 & IDH_pos3 & Nuclear \\
\hline $\mathrm{GTR}+\mathrm{F}+\mathrm{I}+\mathrm{G} 4$ & MDH_pos1 & Nuclear \\
\hline $\mathrm{SYM}+\mathrm{I}+\mathrm{G} 4$ & MDH_pos3 & Nuclear \\
\hline $\mathrm{SYM}+\mathrm{I}+\mathrm{G} 4$ & Nex9_pos1 & Nuclear \\
\hline $\mathrm{K} 3 \mathrm{P}+\mathrm{I}+\mathrm{G} 4$ & Nex9_pos2 & Nuclear \\
\hline $\mathrm{GTR}+\mathrm{F}+\mathrm{R} 6$ & Nex9_pos3 & Nuclear \\
\hline $\mathrm{SYM}+\mathrm{I}+\mathrm{G} 4$ & RpS5_pos1 & Nuclear \\
\hline $\mathrm{GTR}+\mathrm{F}+\mathrm{I}+\mathrm{G} 4$ & WntGeo_pos 1 & Nuclear \\
\hline $\mathrm{SYM}+\mathrm{R} 7$ & WntGeo_pos3 & Nuclear \\
\hline
\end{tabular}

1 
Table 2 (on next page)

Summary of formally proposed taxonomic changes. 


\section{Transfer from Archiearinae to Ennominae}

Acalyphes Turner, 1926, to Ennominae: Diptychini

Dirce Prout, 1910, to Ennominae: Diptychini

\section{Transfer from Oenochrominae to Desmobathrinae:}

Desmobathrini Meyrick, 1886

Nearcha Guest, 1887

Racasta Walker, 1861

Zanclopteryx Herrich-Schäffer, [1855]

\section{Transfer from Oenochrominae to Epidesmiinae:}

Abraxaphantes Warren, 1894

Adeixis Warren 1987

Dichromodes Guenée [1858]

Ecphyas Turner, 1929

Epidesmia Duncan [\& Westwood], 1841

Phrixocomes Turner, 1930

Phrataria Walker, [1863]

Systatica Turner, 1904

\section{New tribe combinations Ennominae}

Psilocladia Warren, 1898, from unassigned to Gonodontini

Oedicentra Warren, 1902, from Boarmiini to Gnophini

Hypotephrina Janse, 1932, from unassigned to Gnophini

Capusa Walker, 1857, from Nacophorini to Diptychini

Mictodoca Meyrick, 1892, from Nacophorini to Diptychini

Furcatrox McQuillan, 1996, from Nacophorini to Diptychini

Amelora Guest, 1897, from Nacophorini to Diptychini

Archephanes Turner, 1926, from Nacophorini to Diptychini

Thalaina Walker, 1855, from Nacophorini to Diptychini

Niceteria Turner, 1929, from Nacophorini to Diptychini

Neazata Warren, 1906 from Caberini to Diptychini

Idiodes Guenée, [1858] from unassigned to Diptychini

Panhyperochia Krüger, 2013, from Nacophorini to Diptychini

Mauna Walker, 1865, from Nacophorini to Diptychini

Pareclipsis Warren, 1894, from unassigned to Diptychini

Crambometra Prout, 1915, from unassigned to Diptychini

Hebdomophruda Warren, 1897, from Nacophorini to Diptychini

Pareclipsis Warren, 1894, from unassigned to Diptychini 
Capasa Walker 1866, from unassigned to Hypochrosini

Omizodes Warren, 1894, from unassigned to Hypochrosini

Metallospora Warren, 1905, from unassigned to Cassymini

Obolcola Walker, 1862, from unassigned to Abraxini

Chelotephrina Fletcher, 1958 from unassigned to Abraxini

Cassephyra Holloway, 1993 from Cassymini to Abraxini

Thenopa Walker, 1855 from unassigned to Drepanogynini

Drepanogynis Guenée, [1858] from Nacophorini to Drepanogynini

\section{New tribe combinations Geometrinae}

Agathiopsis Warren 1896, from unassigned to Hemitheini

Albinospila Holloway 1996, from Geometrini to Hemitheini

Antharmostes Warren 1899, from unassigned to Hemitheini

Ctenoberta Prout 1915, from unassigned to Hemitheini

Comostolopsis Warren 1902, from unassigned to Hemitheini

Oenospila Swinhoe 1892, from Geometrini to Hemitheini

\section{New and upgraded tribes in \\ Included taxa}

Geometrinae

Archaeobalbini, stat. rev.

Type genus: Herochroma Swinhoe, 1893 (syn.

Archaeobalbis Prout, 1912).

Other included genera: Pachyodes Guenée, [1858];

Metallolophia Warren, 1895; Actenochroma Warren, 1893; Absala Swinhoe 1893; Metaterpna Yazaki, 1992; Limbatochlamys Rothschild, 1894; Psilotagma

Warren, 1894; Dindica Warren, 1893; Dindicodes

Prout, 1912; Lophophelma Prout, 1912.

Chlorodontoperini, Murillo-Ramos, Sihvonen \& Brehm, trib. nov.
Type genus: Chlorodontopera Warren, 1893.

Species included: C. discospilata (Moore, 1867); $C$. mandarinata (Leech, 1889); C. chalybeata (Moore, 1872); C. taiwana (Wileman, 1911).

\section{Included taxa}

Drepanogynini, Murillo-Ramos, Sihvonen \& Brehm, trib. nov.
Type genus: Drepanogynis Guenée, [1858].

Other included genera: Thenopa Walker, 1855.

Species included, genus combination uncertain

(incertae sedis): "Sphingomima" discolucida

Herbulot, 1995 (transferred from unassigned to

Drepanogynini); "Hebdomophruda" errans Prout,

1917 (transferred from Nacophorini to

Drepanogynini). 


\begin{tabular}{ll}
\hline Synonymized tribes & Valid tribe \\
\hline Lithinini Forbes, 1948, syn. nov. & Diptychini Janse, 1933 (Ennominae) \\
Synchlorini Ferguson, 1969 syn. nov. & Nemoriini Gumppenberg, 1887 (Geometrinae) \\
\hline Incertae sedis & \\
\hline Eumelea Duncan [\& Westwood], 1841 & \\
\hline Hebdomophruda errans Prout, 1917 & \\
\end{tabular}

